\title{
Prototype Star Fruit-Honey Product and Effectiveness on Antixidants, Inflammation and Walking Distance in Participants with Stable Chronic Obstructive Pulmonary Disease (COPD)
}

\author{
Yothin Pothasak', Jirakrit Leelarungrayub ${ }^{1, *}$, Surapol Natakankitkul ${ }^{2}$, Supawatchara Singhatong ${ }^{3}$
}

Yothin Pothasak', Jirakrit Leelarungrayub ${ }^{1, *}$, Surapol Natakankitkul'2, Supawatchara Singhatong ${ }^{3}$

'Department of Physical Therapy, Faculty of Associated Medical Sciences, Chiang Mai University, Chiang Mai 50200, THAILAND.

${ }^{2}$ Department of Pharmaceutical Science,

Faculty of Pharmacy, Chiang Mai University, Chiang Mai 50200, THAILAND.

${ }^{3}$ Division of Clinical Chemistry, Department of Medical Technology, Faculty of Associated Medical Sciences, Chiang Mai University,

Chiang Mai 50200, THAILAND.

\section{Correspondence}

\section{Jirakrit Leelarungrayub}

Department of Physical Therapy, Faculty of Associated Medical Sciences, Chiang Mai University, Chiang Mai 50200, THAILAND. Phone no. 053-939245;

Fax: (+66) 53936042

E-mail: donrawee.leela@cmu.ac.th History

- Submission Date: 13-04-2020;

- Review completed: 04-05-2020;

- Accepted Date: 25-05-2020.

DOI : 10.5530/pj.2020.12.159

Article Available online http://www.phcogj.com/v12/i5

\section{Copyright}

(c) 2020 Phcogj.Com. This is an openaccess article distributed under the terms of the Creative Commons Attribution 4.0 International license.

\begin{abstract}
Background: Star fruit (Averrhoa carambola L.) is a seasonal fruit, which has proven antioxidant and inflammation activities in vitro. However, sweet-type is more available than sour-type. Therefore, developing a new product from sweet-type star fruit, and evaluating its effectiveness on antioxidants and inflammation have been very challenging. Objectives: The aims were to develop a prototype product from sweet-type star fruit and evaluate its effectiveness with or without walking exercise on participants with stable chronic obstructive pulmonary disease (COPD). Methods: The prototype product of sweet-type star fruit was prepared industrially by mixing with honey before nutrients such as L-ascorbic acid (Vit C) and total phenolic compound, and contaminants like chemicals, microbials and oxalic acid were evaluated. Effectiveness of this product on antioxidents, inflammation and physical function was evaluated in participants with stable COPD with and without walking exercise, and compared to walking exercise and control participants. Two spoons of the product $(20 \mathrm{~g})$ in sterile warm water $(150 \mathrm{~mL})$ were guided and consumed twice daily for 4 weeks, whereas the walking exercise was prescribed with moderate intensity at home for $30 \mathrm{~min} 3$ days per week. Plasma Vit $C$, total antioxidant capacity (TAC), malondialdehyde (MDA), tumor necrotic factoralpha (TNF- $\propto$ ) and 6-minutes walking distance (6MWD) were evaluated before and after the 4-week study period. Results: The prototype product composed of star fruit juice with honey $(1: 1, v: v)$. Main nutrients were composed of ash $(0.4 \mathrm{~g})$, carbohydrate $(74.59 \mathrm{~g})$, lipid $(2.88 \mathrm{~g})$, protein $(0.57 \mathrm{~g})$ and $326.56 \mathrm{kcal}$ of total energy, whereas Vit $\mathrm{C}$ and total phenolic compound were equivalent to $0.25 \pm 0.11 \mathrm{mg}$ and $144.89 \pm 2.51 \mu \mathrm{g}$ gallic acid equivalent in a $100 \mathrm{gram}$ of product. The results of chemicals and microbials showed safety under food conditions. The results of study compared the ages of stable COPD participants between those of the controls $(n=10,69.20 \pm 1.40$ years), and those with star fruit juice and honey supplement ( $n=20,71.25 \pm$ 6.01 years), walking exercise ( $n=15,60.60 \pm 3.38$ years), and supplement with walking exercise $(n=15,64.40 \pm 1.63$ years) and no statistical difference was shown in any parameters in the control group. Whereas, the plasma Vit $C$ and TAC levels increased, and MDA and TNF- $\propto$ levels reduced significantly, in the supplement consumption group, which was in contrast to the Vit C, MDA and TNF- $\propto$ levels in the walking exercise group. However, the TAC level increased significantly when the walking exercise was completed. When the prototype product was applied to the walking exercise, the levels of Vit C and TAC increased, and MDA and TNF- $\propto$ levels reduced significantly. Whereas, the supplement levels increased significantly in all of the groups, especially in the 6MWD. Conclusion: This study proposed that sweet-type star fruit can be prepared industrially by mixing with honey, and be developed as a new commercial product with antioxidant and inflammation activities for participants suffering with chronic lung disease.
\end{abstract}

Key words: Antioxidant, COPD, 6MWD, Oxidative stress, Star fruit product, TNF- $\propto$.

\section{INTRODUCTION}

Chronic obstructive pulmonary disease (COPD) is a major cause of morbidity and mortality worldwide. ${ }^{1}$ It is expected to increase rapidly in northern Thailand. ${ }^{2}$ As the pathophysiology of irreversible disease ${ }^{3}$ causes airway limitation that develops into fibrosis, enlarged alveolar affecting gas exchange and diffusion ${ }^{4}$ can be identified with a clinical pulmonary function test. ${ }^{5}$ Strong evidence reported that chronic inflammation and recurrent infection are related to higher oxidants in COPD patients, ${ }^{6}$ which is consistent with a previous study on the levels of nitric oxide and lipid peroxide in such patients when compared to healthy people, ${ }^{7}$ as well as another report on the high level of malondialdehyde (MDA) from lipid peroxidation and low level of glutathione (GSH) or total antioxidant capacity (TAC). ${ }^{8}$ Although there is less evidence to confirm the relationship between high oxidative stress and low physical function, dominant skeletal dysfunction, muscle atrophy and sarcopenia have been reported, ${ }^{9}$ but unfavorable function and low physical activity were presented in most COPD

Cite this article: Pothasak Y, Leelarungrayub J, Natakankitkul S, Singhatong S. Prototype Star Fruit-Honey Product and Effectiveness on Antixidants, Inflammation and Walking Distance in Participants with Stable Chronic Obstructive Pulmonary Disease (COPD). Pharmacogn J. 2020;12(5):1121-34. 
patients. ${ }^{5}$ Moreover, high oxidative stress reportedly related to high inflammation status in COPD patients. ${ }^{10}$ For instance, previous reports proved that overexpression of tumor necrotic factor-alpha (TNF- $\propto$ ) in the lung induced the release of superoxide radicals from the macrophage or neutrophils, ${ }^{11}$ and a dominantly high level was found in the blood of COPD patients. ${ }^{12}$ Medical treatment can be performed clinically in most COPD patients, with various pharmacological agents such as bronchodilators, which act as $\beta_{2}$-agonists ${ }^{13}$ and anticholinergics, ${ }^{14,15}$ and anti-inflammatory agents such as prednisolone ${ }^{16}$ or a combination of bronchodilator and anti-inflammatory agents like fluticasone ${ }^{17}$ and salmeterol (Advair), ${ }^{18}$ as well as antibiotics, for example, amoxicillin, tetracycline or azithromycin. ${ }^{19}$ However, the non-pharmacological treatments comprise smoking cessation, ${ }^{20}$ education, ${ }^{21}$ oxygen supplement ${ }^{22}$ and pulmonary rehabilitation. ${ }^{23-25}$

Exercise is very important in an overall rehabilitation program for improving physical activity and muscle strength, especially endurance exercise ${ }^{26}$ with high-intensity. ${ }^{27}$ Unfortunately, symptoms are aggravated when heavy exercise is performed because high oxidative stress can be found in most COPD patients under the hypothesis of exercise-induced oxidative stress. ${ }^{28}$ Some studies proposed that endurance exercise at moderate intensity ${ }^{29}$ as well as the interval exercise ${ }^{30}$ or stationary bicycling exercise ${ }^{31}$ could control oxidative stress, but specific local quadriceps endurance exercise at moderate intensity increased the levels of TNF- $\propto$ from inflammatory response, and MDA from lipid peroxidation in ten COPD patients. ${ }^{32}$ Therefore, types of exercise involve oxidative stress and inflammation among COPD statuses, especially on the lower large muscle in the limb such as quadriceps muscles, but exercise still should be encouraged for maintaining or improving physical function. Previous evidence supported the fact that walking exercise is relatively simple and suitable for COPD patients at home, when returning to a sedentary lifestyle. ${ }^{33}$ It also showed benefit in quality of life (QOL) ${ }^{34}$ and exercise tolerance. ${ }^{35}$ On the other hand, some studies showed that walking for six-minutes induced inflammation and oxidative stress in muscle-wasted COPD patients. ${ }^{36}$ Therefore, the beneficial effects of exercise by walking at home had controversial results and conclusions.

Nowadays, antioxidant supplements during exercise are promoted in COPD patients. An updated study in 2019 showed that oral antioxidant supplementation, which comprised tocopherol, ascorbate, zinc gluconate, and selenomethionine during moderate-intensity exercise training for 28 days, increased muscle strength, serum protein, and plasma antioxidant compounds in COPD patients, when compared to non-antioxidant supplementation during exercise training. ${ }^{37}$ Moreover, elderly people showed low antioxidant status, especially in L-ascorbic acid (Vit C), including lower muscle mass, strength and increased walking speed. ${ }^{38,39}$ Previous evidence showed that supplement of Vit $\mathrm{C}$ combined with alpha-tocopherol for 4 weeks decreased the creatine kinase (CK) level in marathon runners, ${ }^{40}$ and furthermore, stimulated the immune function by activating white blood cell proliferation. ${ }^{41}$ Thus, Vit C should be supplemented because of its inability to synthesize endogenously. ${ }^{42}$

Thailand has many fruits and vegetables that have antioxidant activity with possible potential benefits for health, especially in elderly people. Such fruits and vegetables consist of grape peel, garlic and onion, and those with various bioactive compounds such as anthocyanins, lycopene, curcumionids, alpha-tocopherol, and Vit $\mathrm{C}^{43}$ Of all the Thai seasonal fruits, star fruit is very interesting, with its specific characteristics and taste. It has many species or varieties in Asia such as Taiwan (large size with a green edge and sweet taste), China (large size with a white edge and sweet taste), and Malaysia (large size with soursweet taste and much juice).$^{44}$ Previous reviews showed the chemical constituents as saponins, flavonoid C-glycosides, tannin, gallic acid and Vit C. ${ }^{45}$ Previous studies on sour-type star fruit (Averrhoa carambola
L.) in healthy elderly participants $s^{46,47}$ presented antioxidant activity by improving plasma TAC and anti-inflammatory activity by depressing nitric oxide, TNF- $\propto$ and interleukin (IL)-23 release, as well as increasing walking capacity when completing consumption of fresh star fruit juice, twice daily for 4 weeks. Furthermore, the active compounds in sourtype star fruit extract were Vit C and retinoic acid. ${ }^{46}$ Unfortunately, the taste of sour-type star fruit is less popular than that of sweet-type, which is distributed in many areas of Thailand. Updated data showed that active compounds such as total phenolic compound, flavonoids and Vit $\mathrm{C}$ were discovered in sweet-type star fruit extract, which had potential inhibitory effect on TNF- $\propto$ in vitro. ${ }^{48}$ This evidence shows that people suffering with COPD have high oxidative stress and inflammation status, and physical function should be enhanced by simple walking exercise. Therefore, the main objectives of this study were to develop the sweet-type star fruit as a new commercial product, and evaluate its effectiveness on oxidative stress, inflammation and physical function when consumed with or without walking exercise by stable COPD participants.

\section{MATERIALS AND METHODS}

This study was approved by the Ethic Human Committee at the Faculty of Associated Medical Sciences, Chiang Mai University, Thailand (AMSEC-62FB-001). It was conducted in accordance with the Declaration of Helsinki (2001). The protocol in this preliminary study had an experimental design on a new industrial product, which was composed of star fruit juice mixed with honey. The product was randomized in order to evaluate the safety of contaminants (chemicals and microbials), main nutrients and Vit $\mathrm{C}$ content before studying the effectiveness of product consumption on oxidative stress, inflammation and physical function in the COPD participants during 4 weeks of walking exercise. The product was then approved for a registration number from the Food and Drug Administration (FDA). Finally, the side effects from consumption and satisfaction with the product were analized from interviews.

\section{Industrial manufacturing processes}

The product was prepared under pharmaceutical and commercial processes at the Chiang Mai Product, Co., Ltd., Saraphi district, Chiang Mai province, Thailand. Raw sweet-type star fruits (Averrhoa carambola L.), Malaysia variety, were purchased from organic gardens in Pathum Thani province, Thailand. After 2 weeks of baking, they were placed in boxes until ripe, and their fresh juice was manufactured by blending with a fine homogenizer, and all fibers and seeds were removed before keeping in sterilized bottles. The final product was kept in sealed bottles as a trial preparative; manufactured for appropriated physical property under standardized FDA procedure.

\section{Nutrients, VitC, total phenolic compound, contamination and oxalic acid assay}

The product was randomized for evaluating the chemicals and microbial contamination at the Central Laboratory (Thailand), Co., Ltd., Chiang Mai province, Thailand, where the main nutrients such as ash, carbohydrate, protein, lipid, moisture and total energy were identified. The Vit $\mathrm{C}$ in the product was evaluated under a previous protocol. ${ }^{49}$ In order to identify the specific peak of Vit $\mathrm{C}$ in the product at 244 $\mathrm{nm}$ absorbance, the high-performance liquid chromatography (HPLC) technique was carried out with a Sep-pack(t) C18 column (Eclipase Puls C18:5 $\mu \mathrm{mm} \times 4.6 \times 250 \mathrm{~mm}$, Agilent, USA) eluted with $0.1 \%$ of formic acid (HPLC grade) solvent at $0.8 \mathrm{~mL} / \mathrm{min}$. The concentration of Vit $\mathrm{C}$ in the product was calculated by comparing with standard Vit $\mathrm{C}$ (Sigma, St. Louis, MO).

Total phenolic compound in the product was analyzed by following a previous study. ${ }^{50}$ The product was mixed at $50 \mu \mathrm{L}$ with $1.8 \mathrm{~mL}$ of diluted 
Folin-Ciocalteau reagent $(10 \%, v / v)$ (Merck KGaA, Germany), and kept in the dark for $5 \mathrm{~min}$ before $1.2 \mathrm{~mL}$ of (7.5\%) sodium carbonate (Merck, Dermstadt) was added. After being incubated for $60 \mathrm{~min}$, pellets were removed by short centrifugation, and supernatant was read at $765 \mathrm{~nm}$ by spectrophotometry (Drawell Scientific, Changhai). Total phenolic content was calculated and compared to standard gallic acid (0.008-1.0 $\mathrm{mg} / \mathrm{mL}$ ) (Fluka, Switzerland). Contamination with chemicals such as benzoate, sorbic acid, salicylic acid, saccharin and synthetic color, and disease-induced microbials, for instance, MPN Coliforms, Escherichia coli, Yeast, Fungi, Salmonela sp. Clostridium perfringens, Staphylococcus aureus and Bacillus cereus were investigated in the laboratory under the Public Health Guideline (Issue: 356) (2013) of the Department of Medical Sciences, Thailand.

Whereas, oxalic acid in the product was evaluated under the protocol of Wilson's study. ${ }^{51}$ Before identifying oxalic acid, the product was hydrolyzed with hydrochloric acid (HCL) (1 molar) for $15 \mathrm{~min}$ in hot water (100C). The oxalic acid peak was identified with the same HPLC column as that used in the protocol for Vit $\mathrm{C}$ analysis, but with mixed solvent of water with acetonitrile $(8: 2, v: v)$ containing $0.1 \%$ propionic acid. The oxalic acid peak was shown with $220 \mathrm{~nm}$ absorbance and a $1.0 \mathrm{~mL} / \mathrm{min}$ flow rate, and oxalic acid concentration in the product was calculated with the standard curve of standard oxalic acid (Sigma, St. Lousi, MO).

\section{Effectiveness of the Product on the participants with COPD during the walking exercise}

\section{Subject design}

The sample size in this study was calculated from a previous one, ${ }^{52}$ which studied the effectiveness of supplementation with Vit $\mathrm{C}$ on TAC in 13 COPD patients under the $\mathrm{G}^{*}$ Power (3.1.9.2) program; 0.92 of effect size, 0.05 of alpha error and 0.85 of power with t-test (Means: Difference between two dependent means). Then, fifteen participants in this study were placed in each of four groups. This study was performed at Baan Tor- and Pukka-Health Promotion Hospitals, San Sai district, Chiang Mai province, Thailand. All of the participants had been diagnosed as COPD at San Sai Hospital following the guideline of the Global Initiative for Chronic Obstructive Lung Disease (GOLD). Furthermore, the participants were stable and controlled by medication in the form of either a long acting inhaled bronchodilator or long inhaled steroids from the hospital. All of the participants were exsmokers and in stable clinical condition during the experiments. If they showed uncontrolled hypertension, unstable cardiac disease, recurrent symptoms of pneumothorax, thoracic or chest pain including neuromuscular disorders, liver diseases or endocrinal abnormalities, they were excluded from this study. Moreover, participants also were excluded if taking extra-supplements or any nutrients such as vitamins or energy-enriched beverage or food during this study.

Finally, all of the participants signed a written consent form before the program started. In order to the evaluate effectiveness of the product supplement during walking exercise, the four groups were designed by randomized protocol; 1) control, 2) supplement, 3) walking exercise, and 4) supplement with walking exercise.

\section{Dependent and Independent Variables}

The dependent variables in this study were separated into four groups:

I. Control Group: No supplement or walking exercise.

II. Supplement Group: Strict prescription of two teaspoons (10 grams totally) of the product supplement in a $150 \mathrm{~mL}$ cup of warm water, taken twice daily after meals for 4 weeks.

III. Exercise Group: Home-based evening walking exercise 30 min daily for 4-weeks, at moderate intensity with moderate to severe sensation of dyspnea (4-5 from a maximal scale of 10).

IV. Supplement with Exercise Group: Supplement with walking exercise for 4 weeks as detailed in II and III dependents.

The independent variables in this study were oxidative stress (TAC and lipid peroxides), inflammation ( TNF- $\propto$ ) variables, as well as the variable on physical function: 6-minute walking distance (6MWD).

\section{Variable assay protocols}

A total of $10 \mathrm{~mL}$ of blood was taken from the anterior cubital vein, with $5.0 \mathrm{~mL}$ of that taken by a Medical Technologist and transferred to sterile ethylenediamine tetraacetic acid (EDTA) and non-EDTA tubes for evaluating renal function and fasting blood sugar at the AMS Clinical Service Center, Faculty of Associated Medical Sciences, Chiang Mai University, Thailand. Residual blood was centrifuged to separate the plasma for detecting Vit C, TAC, MDA, TNF- $\propto$ and oxalic acid.

Plasma Vit C was evaluated under HPLC. ${ }^{49}$ Briefly, $100 \mu \mathrm{L}$ of plasma was precipitated with $400 \mu \mathrm{L}$ of $60 \%$ ethanol containing EDTA $(1.0$ $\mathrm{mmol} / \mathrm{L})$. After $200 \mu \mathrm{L}$ of supernatant was evaporated by high speed centrifuge, $100 \mu \mathrm{L}$ of ethanol containing $100 \mu \mathrm{g}$ of standard Vit $\mathrm{C}$ was resolved before identifying Vit $\mathrm{C}$ under the HPLC system (Eclipase Plus C18 Column, $5 \mu \mathrm{m}, 4.6$ x $250 \mathrm{~mm}$ Agilent, USA; 0.1\% formic acid, Sigma-Aldrich, Germany; $0.8 \mathrm{~mL} / \mathrm{min}$ of flow rate, and $244 \mathrm{~nm}$ absorbance). The Vit $\mathrm{C}$ in plasma was calculated by comparing with the standard curve peak of Vit C (Fisher Scientific, UK).

Plasma TAC was evaluated following the modified protocol in a previous study $^{47}$ under the original 2, 2-azino-bis-3-ethylbenzothiazoline-6sulfonic acid (ABTS) decolorization method. ${ }^{53}$ The TAC of plasma on scavenging $\mathrm{ABTS}^{*+}$ was produced by reacting ABTS (CALBIOCHEM, Darmstadt, Germany) with potassium persulfate (Merck KGaA, Darmstadt, Germany) in deionized water. Initial absorbance at 900 $\mu \mathrm{L}$ of $\mathrm{ABTS}^{*+}$ and at $734 \mathrm{~nm}$ and $0.7 \pm 0.02$ was set before adding 10 $\mu \mathrm{L}$ of plasma. The percentage of maximal reduction of absorbance was calculated by spectrophotometry. Then, the plasma TAC was represented as millimoles of standard Trolox per liter of plasma ( $\mathrm{mmol}$ Trolox/L).

Plasma MDA from lipid oxidation was evaluated by following a previous method, ${ }^{54}$ with the protocol of HPLC under the thiobarbituric acid reactive substances (TBARs) test. A $200 \mu \mathrm{l}$ of plasma was mixed with $750 \mu \mathrm{l}$ of ortho-phosphoric acid $(2.5 \%, \mathrm{v} / \mathrm{v})$ and $200 \mu \mathrm{L}$ of thiobarbituric acid $(0.2 \mathrm{~mol} / \mathrm{L})$ solution. After 30 minutes of heating at $90^{\circ} \mathrm{C}$, short high-speed centrifugation was carried out at 10,000 rpm in room temperature in order to remove all pellets. Clear yellowed supernatant of TBARs-MDA adduct was injected into the rheodyne valve with a $10 \mu \mathrm{L}$ fixed loop. The peak of TBARs-MDA complex was identified at $532 \mathrm{~nm}$ by a C- 18 reverse-phase column (Eclipase Plus C18 Column, 5 $\mu \mathrm{m}, 4.6 \times 250 \mathrm{~mm}$ Agilent, USA) under an isocratic methanol (HPLC grade) mobile phase, with a flow rate of $1.0 \mathrm{~mL} / \mathrm{min}$, expressed as equal to the MDA concentrations, which were calculated by comparing with standard tetra-methoxypropane (Sigma-Aldrich Co.).

Plasma TNF- $\propto$ was evaluated following the guidelines in the Quantikine, Human TNF- $\propto$ (Quantikine ${ }^{\oplus}, \mathrm{R} \& \mathrm{D}$ systems, Inc, Minneapolis, MN, USA). One hundred microliters of diluent solution with $50 \mu \mathrm{L}$ of external standard TNF- $\propto(100 \mathrm{pg} / \mathrm{mL})$ was loaded onto an anti- TNF- $\propto$ polyclonal antibody-immobilized solid phase and incubated for $2 \mathrm{~h}$ at room temperature, before washing 4 times with $400 \mu \mathrm{L}$ of specific washing buffer. Two hundred microliters of horseradish peroxidase (HRP) conjugated TNF- $\propto$ solution was added to each respective well before incubating at room temperature for 2 $\mathrm{h}$, and gently aspirating and washing three times with washing buffer prior to adding $400 \mu \mathrm{L}$ of tetra-methylbenzidine (TMB) substrate. A blue color developed and was presented after incubating for $20 \mathrm{~min}$ 
at room temperature. The final process was to stop the reaction by using $50 \mu \mathrm{L}$ of $2 \mathrm{~N}$ sulfuric acid. A yellow color was presented and absorbance detected at $450 \mathrm{~nm}$ within $30 \mathrm{~min}$. Concentration of the TNF- $\propto$ in plasma was calculated by comparing with the standard curve of standard TNF- $\propto(15.6-1,000 \mathrm{pg} / \mathrm{mL})$.

The 6MWD was evaluated from the standardized guide of the American Thoracic Society (ATS) protocol (2002), ${ }^{55}$ which was modified from the 20 -meter straight walking test performed in an outside corridor. Any vigorous physical activities and eating $2 \mathrm{~h}$ before starting the $6 \mathrm{MWD}$ were avoided under the testing recommendation of the American College Society of Medicine (ACSM, 2014). ${ }^{56}$ Comfortable clothes and shoes could be worn during the test, and vital signs such as heart rate, blood pressure, respiratory rate and oxygen saturation were evaluated for safety reasons before and after the test.

\section{Side effects and satisfaction evaluation}

Renal function (blood urea nitrogen; BUN and creatinine) and fasting blood sugar (FBS) tests that evaluated the side effects from product consumption, were standardized and performed by a fully automated Olympus AU400 Analyzer (Olympus Diagnostics GmbH, Umkirch, Germany) at the AMS Clinical Service Center, Faculty of Associated Medical Sciences, Chiang Mai University, Chiang Mai, Thailand.

The oxalic acid level in plasma was evaluated with the HPLC system under a previous protocol. ${ }^{51}$ The protein in plasma was precipitated with HCL $(1.0 \mathrm{~mol} / \mathrm{L})$ in a heated water bath before identifying oxalic acid in a reversed-phase $\mathrm{C} 18$ column with mobile phase (water: acetonitrile, $8: 2$ and $0.1 \%$ propionic acid) at $1.0 \mathrm{~mL} / \mathrm{min}$ of flow rate. The specific peak of oxalic acid in plasma was compared to peaks of standard oxalic acid that were identified at $220 \mathrm{~nm}$ absorbance.

Symptomatic adverse effects such as vomiting, confusion, vertigo, numbness, or hiccups were assessed weekly by telephone interview. Five categories of symptoms such as none, mild, moderate, sever or very severe were questioned. Finally, satisfaction with the product on taste, product and color appearance also was assessed by interview with five categories; excellent, good, moderate, mild and bad at the end of the 4-week study.

\section{Statistical analysis}

All of the data were analyzed statistically for normal distribution using the One-sample Kolmogorov-Smirnov test before presenting as mean, with standard error or mean (SM), and minimal and maximal values. Characteristics and pulmonary function between the four groups were analyzed by the One-way ANOVA test. Whereas, independent variables between the groups were analyzed before and after the 4-week study period by repeated ANOVA measurement (4 groups and 2 times) and the Bonferroni post hoc test. All statistical analyses were carried out using the statistical package for social science software (SPSS) version 11.0 (SPSS Inc. Chicago, IL, USA) for Windows. All of the tests were used with significance at $\mathrm{p}<0.05$.

\section{RESULTS}

In order to evaluate the benefits of star fruit juice with honey on health status among people with stable COPD, this product was designed strictly and developed in the food industry. When, this industrial product had been manufactured, the microbial and heavy metal contamination in it was standardized and tested in order to obtain an FDA registration number. Finally, effectiveness of the product on inflammatory antioxidant and walking capacity of the participants with stable COPD was analyzed during walking exercise at home.
Development of the product, contamination, Vit $\mathrm{C}$ and total phenolic content

The product in this study was manufactured industrially at the Chiang Mai Healthy Product Co., Ltd., Chiang Mai, Thailand. From industrial preparation of the product, the volume ratio was appropriated equally between star fruit juice and raw sterile honey, produced by Siam Weed (Eupatorium odoratum L.) in a large mixed chamber for $1 \mathrm{~h}$, and evaporated under pressure at $65 \mathrm{~cm} / \mathrm{Hg}$ for $2 \mathrm{~h}$ and $30 \mathrm{~min}$ at $50^{\circ} \mathrm{C}$, until the final humidity reached $21 \%$. The end product was kept in a sealed sterile bottle at 250 grams per bottle (Figure 1).

\section{Main nutrient, Vit $C$ and total phenolic compound results}

Results of the standardized laboratory tests on the industrially manufactured product gave a sample code of CM62/01365-001 at the Central Laboratory (Thailand) Co., Ltd., Chiang Mai, Thailand. All of the protocols for nutrient assessment followed the standardized method of the $2010^{57}$ and $2016^{58}$ Association of Official Analytical Chemist (AOAC) and the 2003 Compendium of Method for Food analysis. ${ }^{59}$ When five from all of the bottles were identified for sampling, the main nutrients in 100 grams of the product were composed of ash (0.40), carbohydrate (74.59), lipid (2.88) and protein (0.57), and a total 326.56 kcal of energy (Table 1).

The results of Vit $\mathrm{C}$ evaluation under the HPLC protocol showed the peak of standard Vit $\mathrm{C}$ at $3.86 \mathrm{~min}$ and $244 \mathrm{~nm}$ absorbance, and concentration within the standard curve was $10-80 \mathrm{mg} / \mathrm{mL}$. Then, Vit $\mathrm{C}$ and total phenolic compound in the product was $0.25 \pm 0.11 \mathrm{mg}$ at 100 grams (Figure $2 \mathrm{~A}$ ) and $144.89 \pm 2.51 \mu \mathrm{g}$ gallic acid equivalent (GAE).

\section{Chemicals, microbial contamination and oxalic acid content}

The results of chemicals and microbial analysis from the Department of Medical Sciences, Ministry of Public Health, Mae Rim, Chiang Mai, Thailand, were reported as document number 6202226 under the sample code of 35620100001 (Beverage sealed container). The chemicals and important microbial contamination were identified under notification of the Ministry of Public Health (NO. 356) B.E. (2013). The results in Table 2 show no chemicals, such as benzoate, sorbic acid, salicylic acid, saccharin or synthetic color, when following the standardized protocol of the in-house method, based on the International Organization for Standardization (ISO) $22855-2008$ or the protocol in a previous study: Anal. Chim Act 583; 2007, pp.103-110. In addition, the results of microbial contamination under the Bacteriological Analytical Manual (BAM) and American Public-Health Association (Ry) guidelines showed that Escherichia coli, Staphylococcus aureus and Salmonella spp. were undetectable in the product, whereas Coliform, MPN, Yeast and Mold and Bacillus cereus had safety limitations. Finally, the product was approved legally for safe consumption from the FDA and Ministry of Public Health, Thailand, with the Food Serial Number of 50-1-022372-0122. The result of oxalic acid content in the product was identified by following the previous protocol of Wilson et $\mathrm{al}^{51}$ under the HPLC. Oxalic acid peak from the HPLC protocol was shown at $4.35 \mathrm{~min}$ and $214 \mathrm{~nm}$ absorbance, and the concentrations within the standard curve were $0.15-350 \mathrm{mg} / \mathrm{L}$. The product contained $0.25 \pm 0.11 \mathrm{mg}$ of oxalic acid at 100 grams (Figue 2B).

\section{Effectiveness of the product on participants with COPD}

The participants were divided randomly into four groups: control $(\mathrm{n}=10)$, walking exercise $(\mathrm{n}=15)$, supplement $(\mathrm{n}=15)$, and supplement with walking exercise $(n=15)$. However, five more COPD participants self-volunteered for the supplement group, in which a total of 20 participants were therefore recruited. When the characteristic data of 
all groups was distributed, and analyzed using the Komogorov-Smirnov test, normal distribution was presented. Thus, the mean and standard deviation of each datum are shown in Table 3.

The characteristic data of each group are shown in Table 3. The ages of the four groups showed significant differences between the control, supplement, walking exercise, and supplement with walking exercise group $(\mathrm{p}<0.05) ; 69.20 \pm 1.40,71.25 \pm 6.01,60.60 \pm 3.38$ and $64.40 \pm 1.63$ years old, respectively). The participants in the walking exercise group were significantly younger than those in the control $(\mathrm{p}=0.046)$ and supplement $(\mathrm{p}=0.034)$ group, but they had no-significant difference in age from the supplement with walking exercise group. Height between the four groups showed significant differences $(\mathrm{p}<0.05)$; $157.20 \pm 3.13$, $167.80 \pm 2.65,153.50 \pm 1.83$ and $156.87 \pm 2.55 \mathrm{~cm}$, respectively). As with the result of age, height of the participants in the walking exercise group was significantly different when compared to that in the supplement $(\mathrm{p}=0.001)$ and supplement with walking exercise group $(\mathrm{p}=0.028)$, but non-significant to the control group. However, weight between the groups had no significant difference $(\mathrm{p}=0.365) ; 56.50 \pm 3.73,58.40 \pm$ $4.41,50.70 \pm 2.78$ and $51.60 \pm 3.48 \mathrm{~kg}$, respectively), as well as body mass index (BMI) $(\mathrm{p}=0.627) ; 23.46 \pm 2.27,20.54 \pm 1.13,21.74 \pm 1.37$ and $20.85 \pm 1.18$, respectively).

The baseline $\mathrm{p}$ values of pulmonary functions between the groups such as forced vital capacity (FVC) ( $\& \%)(\mathrm{p}=0.394 \& 0.249)$ and forced expiratory volume in one second ( FEV1) $(\mathrm{L} \& \%)(\mathrm{p}=0.503 \& 0.54)$ were not statistically different, except for the $\mathrm{p}$ values of FEV1/FVC ( $\mathrm{p}$ $=0.002 \& 0.005)$. The FEV1/FVC of participants in the walking exercise group was significantly lower than that in the control group $(p=0.002)$, as in the result between the supplement with walking exercise and control group ( $\mathrm{p}=0.017)$. When observed, the pulmonary function test (PFT) data had various COPD stages from mild to moderate severity, and FVC \% data in some participants were more than $80 \%$ in each group.

The results of antioxidants in all parameters before and after the 4-week period are shown in Table 4 and Figure 3. The results of baseline plasma Vit $\mathrm{C}$ between the groups were statistically different $(\mathrm{p}=0.032)$, especially between the walking exercise and supplement group ( $\mathrm{p}=$ 0.027). In addition, the plasma TAC and MDA between the four groups at baseline showed no statistical difference ( $p=0.117 \& 0.297)$, the same as the results of TNF- $\propto(\mathrm{p}=0.415)$ and 6MWD $(\mathrm{p}=0.081)$.

When the 4-week study period was completed, all of the parameters showed no statistical change in the control group. The supplement group showed that the plasma Vit $C$ level increased $(p=0.012)$, the same as the result of TAC $(p=0.012)$, whereas the levels of MDA and TNF- $\propto$ reduced significantly $(\mathrm{p}=0.000 \& 0.000)$. In addition, those levels were significantly lower when compared to the control group $(\mathrm{p}$ $=.000 \& 0.023$ ).

The walking exercise group showed a significantly decreased Vit $\mathrm{C}$ level $(\mathrm{p}=0.000)$ and increased MDA $(\mathrm{p}=0.000)$ and TNF- $\propto(\mathrm{p}<$ $0.000)$ levels, but the TAC level increased significantly $(\mathrm{p}=0.000)$ when compared to pre intervention. Moreover, the levels of MDA and TNF$\propto$ also were significantly higher in this group when compared to the supplement group $(\mathrm{p}=0.000)$.

Results in the supplement with walking exercise group showed significantly increased plasma Vit $C(p=0.004)$ and TAC $(p=0.000)$ levels, while decreased MDA level $(\mathrm{p}=0.000)$. However, the level of TNF- $\propto$ did not decrease significantly when compared to before the study period. When comparing between the other groups, the level of TAC also was significantly higher than that in the control $(p=0.000)$ and supplement group $(\mathrm{p}=0.033)$, which was the same as MDA results when comparing with the control group $(p=0.00)$ and TNF- $\propto$ compared to the control $(\mathrm{p}=0.003)$ and walking exercise group $(\mathrm{p}=0.003)$.

Results of the 6MWD represented physical function, which increased significantly in all of the groups $(p<0.05)$, except for the control group $(\mathrm{p}=0.05)$. There was no significant difference before the study $(p=0.081)$, whereas significant difference occurred between the groups during the 4 -week study period $(\mathrm{p}=0.008)$, especially in the $6 \mathrm{MWD}$ in the supplement with walking exercise group.

\section{Renal function, blood sugar and oxalic acid levels}

Results of renal function, blood sugar and oxalic acid tests, which might contain adverse effects from this product supplementation, are presented in Table 5 .

In addition, results of the renal function test in either blood urea nitrogen (BUN) or creatinine showed no statistical difference between the groups before $(p>0.05)$ or after the 4 -week period $(p>0.05)$, which was the same as the creatinine results. There was no statistical difference between the groups at the baseline $(p>0.05)$ when fasting blood sugar was evaluated. The glucose levels increased slightly after the 4 -week period in both groups that took the product supplement, but there was no statistical difference $(p>0.05)$. Oxalic acid in plasma was identified in all of the groups either before or after the 4-week period. Oxalic acid could not be detected in any of the groups, except for the supplement

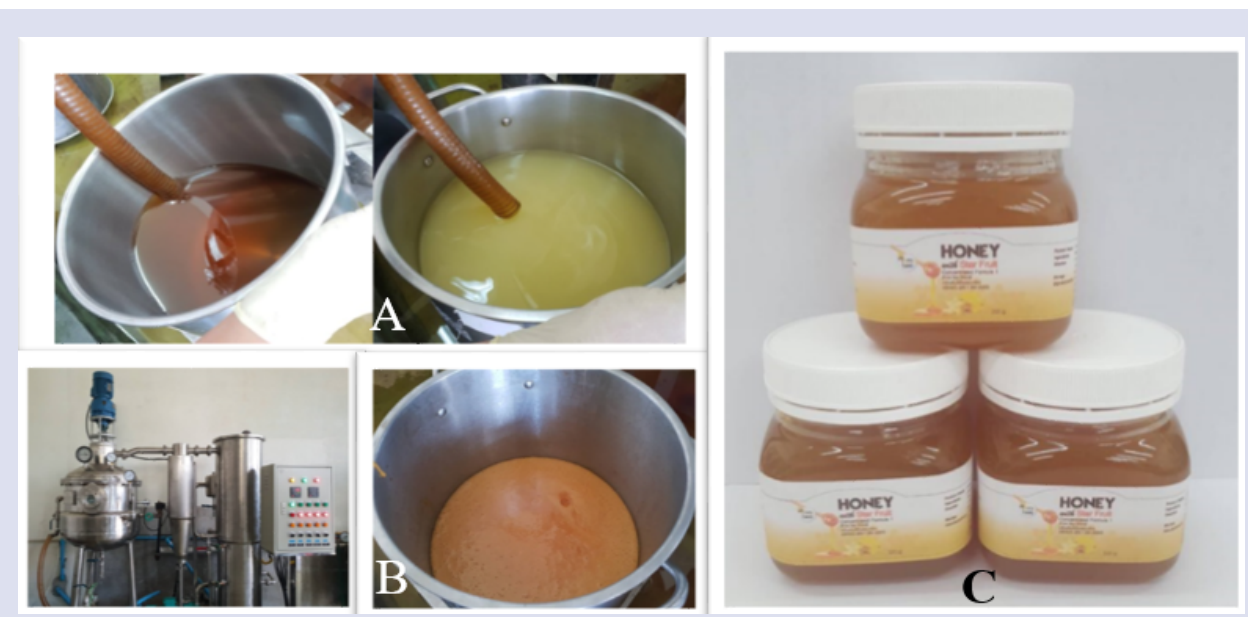

Figure 1: Product manufacturing process by mixing the star fruit juice with raw honey $(A)$ in a large sterile pot for $1 \mathrm{~h}$, (B) before evaporating to $21 \%$ humidity, and (C) keeping in 250-gram sterile bottles. 
and supplement with walking exercise group when the 4-week period was completed, with no statistical difference shown between the groups $(\mathrm{p}>0.05)$.

\section{Symptomatic adverse effects and satisfaction with product consumption}

There were no adverse or side effects in this study such as vomiting, confusion, vertigo, numbness or hiccups from product consumption in the supplement $(\mathrm{n}=20)$ or supplement with walking exercise group $(\mathrm{n}=15)$ over the 4-week study period. Moreover, all of the participants claimed that the taste, and product appearance and color were excellent.

\section{DISCUSSION}

This was a preliminary study on the seasonal sweet-type star fruit that has good characteristics and a special taste when prepared industrially in Thailand. Previous data on extract from sour-type star fruit showed high Vit $\mathrm{C}$ and low retinoic acid (Vit A), and fresh juice supplement taken twice daily for 4-weeks benefited antioxidant and pro-inflammation status in elderly people. ${ }^{46}$ Unfortunately, sour-type star fruit is rare and cultivated less in Thailand, whereas the sweet-type is more popular in the country, with its larger size and sweet taste, which is suitable for product development in the future. Updated preliminary evidence on sweet-type star fruit extract shows activities of radical scavenging as well as suppressed inflammation through inhibiting TNF- $\propto$ in vitro. ${ }^{48}$ Many famous food products from the partner industry; Chiang Mai Healthy Product Co., Ltd. (Thailand), have been developed for mainly honey from base material of the raw wild flower, Eupatorium odorata L. Therefore, star fruit juice supplement was developed by mixing industrially with honey. This study mixed star fruit juice with honey at a 1:1 ratio by volume, and evaporated it under pressure for $2 \mathrm{~h}$ and 30 min at $65 \mathrm{~cm} \mathrm{Hg}$ and $50^{\circ} \mathrm{C}$ for final humidity of $21 \%$, because humidity higher than $60 \%$ affects the growth of yeast and fungi..$^{60}$ Moreover, the results of chemical and microbial contamination were according to the safety policy of the Department of Public Health, Thailand under FDA guidelines (updated 12/2019), which validated the analytical methods used for detecting microbial pathogens in food and feed, especially coliforms, Escherichia coli, yeast, fungi, Salmonela sp, Clostridium perfringens, Staphylocossus aureus and Bacillus cereus that induce diarrhea and septicemia. In addition, the main nutrient was analyzed under the $2010^{57}$ and $2016^{58}$ AOAC. Although there was less Vit $\mathrm{C}$ in sweet-type star fruit ${ }^{48}$ than sour-type ${ }^{47}, 2.098 \mathrm{mg}$ of Vit $\mathrm{C}$ could be detected in $250 \mathrm{mg}$ of the product.

On the other hand, oxalic acid must be of concern for consumers because of its high content in star fruit, which relates to neurotoxic or neuphrotoxic conditions. ${ }^{61} \mathrm{~A}$ previous report showed that oxalic acid contributes proportionately in some vegetables such as rhubarb, spinach and beet in English diets, ${ }^{62}$ to the end product of ascorbate, glyoxylate and glycine metabolism in mammals. ${ }^{63}$ The minimal dose of oxalate causing death in adults was reportedly $4-5$ grams. ${ }^{64}$ In addition, oxalate is absorbed poorly under non-fasting conditions, and only $2-12 \%$ of it is absorbed from foods. Residual free oxalate can bind to calcium ions to form insoluble calcium oxalate, and then precipitate in the urine and may form kidney stones. ${ }^{65}$ However, the product contained 100 grams of oxalic acid, which is equal to 0.625 milligram and a very low content when administering only 20 grams per dose. Therefore, the oxalic acid dose probably was very safe. The overall data on chemicals, microbial contamination and nutrients was approved by the Central Laboratory Ltd., with a Food serial number of 50-1-02237-2-0122 before studying the participants.

Stable COPD patients were recruited for this study and randomized into three groups of 15 participants per group: supplement, walking exercise and supplement with walking exercise groups. In addition, 10

Table 1: Main nutrients in the product composed of star fruit juice with honey.

\begin{tabular}{ccl}
\hline Parameters & Results & \multicolumn{1}{c}{ Method } \\
\hline Ash (g) & 0.40 & AOAC (2016) 923.03 and 920.153 \\
Carbohydrate (g) & 74.59 & Compendium of Method for Food analysis. $1^{\text {st }}$ Edition. 2003 \\
Lipid (g) & 2.88 & AOAC (2016) 948.15 \\
Protein (\%Nx6.25) (g) & 0.57 & AOAC (2016) 991.20 \\
Moisture (g) & 21.56 & AOAC (2010) 969.38 \\
Energy (kcal) & 326.56 & Compendium of Method for Food analysis. 1 $^{\text {st }}$ Edition. 2003 \\
\hline
\end{tabular}

Note: $\mathrm{AOAC}=$ Association of Official Analytical Chemist.
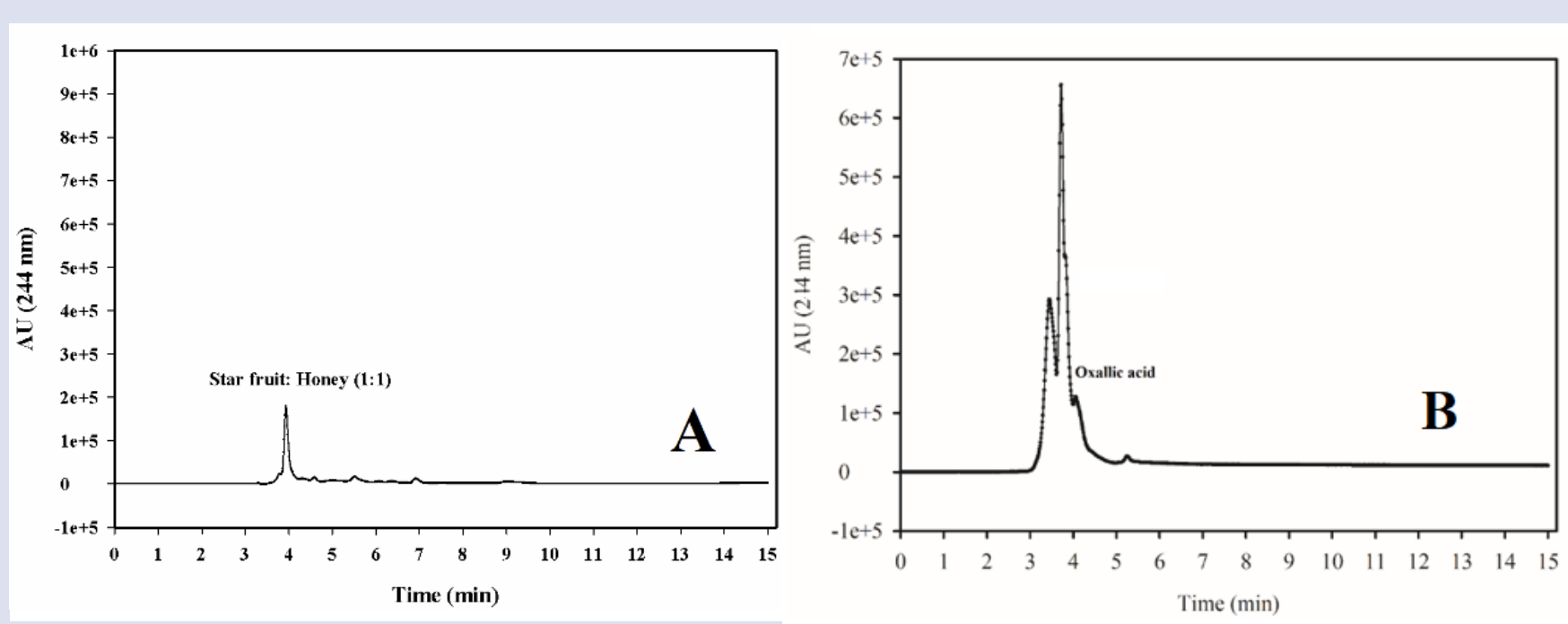

Figure 2: L-ascorbic acid (A) and oxalic acid (B) peaks in the product. 
Pothasak, et al:: Prototype Star Fruit-Honey Product and Effectiveness on Antixidants, Inflammation and Walking Distance in Participants with Stable Chronic Obstructive Pulmonary Disease (COPD)

Table 2: Chemicals and microbial contamination in the product.

\begin{tabular}{|c|c|c|c|}
\hline Parameters & Results & Reference & Method \\
\hline Benzoic acid (mg/kg) & UR & $<200$ & In-house method based on ISO 22855:2008 \\
\hline Sorbic acid (mg/kg) & UR & $<200$ & In-house method based on ISO $22855: 2008$ \\
\hline Salicyclic acid (mg/kg) & UR & Banned & In-house method based on ISO 22855:2008 \\
\hline Saccharin $(\mathrm{mg} / \mathrm{kg})$ & UR & - & In-house method based on ISO $22855: 2008$ \\
\hline Synthetic color (mg/kg) & UR & Depends on color type & In-house method based on Anal. Chim. Acta. 583,2007, pp 103-110. \\
\hline Coliform, MPN/100 ml & $<1.1$ & $<2.2$ & APHA 9221B:2017, BAM 2017, chapter 4 \\
\hline Yeast and Mold/ $1 \mathrm{~g}$. & $<10$ & Depends on the process & APHA, Compendium 2015, chapter 21 \\
\hline Escherichia coli/ $1 \mathrm{~g}$. & UR & Should not be detected & BAM 2017, chapter 4 \\
\hline Bacillus cereus/ $1 \mathrm{~g}$. & 60 & $<100$ & BAM 2012, chapter 14 \\
\hline Staphylococcus aureus/ $0.1 \mathrm{~g}$. & UR & Should not be detected & BAM 2015, chapter 12 \\
\hline Salmonella spp./ 25 g. & UR & Should not be detected & ISO 6579-1: 2017 \\
\hline
\end{tabular}

Note: UR = undetectable result

Table 3: Characteristics and pulmonary function of all of the participants.

\begin{tabular}{|c|c|c|c|c|c|}
\hline Parameters & Control & Supplement & Exercise & $\begin{array}{l}\text { Supplement } \\
+ \text { Exercise }\end{array}$ & $p$ \\
\hline $\mathrm{n}$ (male: female) & $10(5: 5)$ & $20(8: 12)$ & $15(10: 5)$ & $15(8: 7)$ & \\
\hline Age (years) & $\begin{array}{l}69.20 \pm 1.40 \\
(62-76)\end{array}$ & $\begin{array}{l}71.25 \pm 6.01 \\
(61-82)\end{array}$ & $\begin{array}{l}60.60 \pm 3.38 \\
(49-77)\end{array}$ & $\begin{array}{l}64.40 \pm 1.63 \\
(49-75)\end{array}$ & 0.001 \\
\hline Weight (kg) & $\begin{array}{l}56.50 \pm 3.73 \\
(43-74)\end{array}$ & $\begin{array}{l}50.70 \pm 2.78 \\
(33-74)\end{array}$ & $\begin{array}{l}58.40 \pm 4.41 \\
(42-76)\end{array}$ & $\begin{array}{l}51.60 \pm 3.48 \\
(30-84)\end{array}$ & 0.365 \\
\hline Height $(\mathrm{cm})$ & $\begin{array}{l}157.20 \pm 3.13 \\
(145-175)\end{array}$ & $\begin{array}{l}153.50 \pm 1.83 \\
(140-175)\end{array}$ & $\begin{array}{l}167.80 \pm 2.65 \\
(160-180)\end{array}$ & $\begin{array}{l}156.87 \pm 2.55 \\
(141-170)\end{array}$ & 0.002 \\
\hline BMI $\left(\mathrm{kg} \cdot \mathrm{m}^{-2}\right)$ & $\begin{array}{l}23.46 \pm 2.27 \\
(16-32.9)\end{array}$ & $\begin{array}{l}21.74 \pm 1.37 \\
(14-32.9)\end{array}$ & $\begin{array}{l}20.54 \pm 1.13 \\
(15.4-23.5)\end{array}$ & $\begin{array}{l}20.85 \pm 1.18 \\
(13.7-31.1)\end{array}$ & 0.627 \\
\hline FVC (L) & $\begin{array}{l}2.44 \pm 0.30 \\
(1.43-4.11)\end{array}$ & $\begin{array}{l}1.93 \pm 0.19 \\
(0.9-3.79)\end{array}$ & $\begin{array}{l}2.37 \pm 0.36 \\
(1.47-3.98)\end{array}$ & $\begin{array}{l}2.36 \pm 0.24 \\
(1.04-3.94)\end{array}$ & 0.394 \\
\hline FVC (\%) & $\begin{array}{l}92.0 \pm 23.58 \\
(66-131)\end{array}$ & $\begin{array}{l}84.5 \pm 5.05 \\
(49-122)\end{array}$ & $\begin{array}{l}71.9 \pm 5.96 \\
(51-95)\end{array}$ & $\begin{array}{l}85.4 \pm 6.09 \\
(45-126)\end{array}$ & 0.249 \\
\hline FEV1 (L) & $\begin{array}{l}1.66 \pm 0.17 \\
(1.1-2.52)\end{array}$ & $\begin{array}{l}1.28 \pm 0.14 \\
(0.49-2.62)\end{array}$ & $\begin{array}{l}1.37 \pm 0.31 \\
(0.57-2.77)\end{array}$ & $\begin{array}{l}1.48 \pm 0.14 \\
(0.57-2.44)\end{array}$ & 0.503 \\
\hline FEV1 (\%) & $\begin{array}{l}81.0 \pm 5.91 \\
(57-110)\end{array}$ & $\begin{array}{l}68.9 \pm 5.4 \\
(37-114)\end{array}$ & $\begin{array}{l}52.2 \pm 8.37 \\
(35-85)\end{array}$ & $\begin{array}{l}68.1 \pm 5.25 \\
(39-101)\end{array}$ & 0.054 \\
\hline FEV1/FVC & $\begin{array}{l}0.70 \pm 0.23 \\
(0.54-0.77)\end{array}$ & $\begin{array}{l}0.64 \pm 0.02 \\
(0.45-0.78)\end{array}$ & $\begin{array}{l}0.53 \pm 0.05 \\
(0.3-0.7)\end{array}$ & $\begin{array}{l}0.63 \pm 0.02 \\
(0.5-0.74)\end{array}$ & 0.002 \\
\hline FEV1/FVC (\%) & $\begin{array}{l}84.6 \pm 2.24 \\
(69-93)\end{array}$ & $\begin{array}{l}77.2 \pm 2.71 \\
(53-96)\end{array}$ & $\begin{array}{l}64.6 \pm 5.92 \\
(37-86)\end{array}$ & $\begin{array}{l}76.2 \pm 2.16 \\
(61-90)\end{array}$ & 0.005 \\
\hline
\end{tabular}

Note: $\mathrm{BMI}=$ body mass index, FVC = forced vital capacity, FEV1 = forced expiratory volume in one second. The p value was analyzed statistically with One-way ANOVA.

participants also were recruited as a control group. Characteristics from the statistical analysis showed differences in age and height between the groups, especially in the walking exercise and combined walking exercise with supplement group, when compared to the control and supplement group. These results were limited to participants who were able to exercise at home. Furthermore, the participants were very interested in the new prototype of sweet-type star fruit with honey, thus, five of them volunteered to be in the supplement group. Therefore, a total of 20 participants were studied in the supplement group. The statistical difference in pulmonary functions was presented between the groups, especially regarding the FEV1/FVC ratio and \% in the walking exercise group, because more participants $(n=4)$ in that group classified under the 2017 guideline of GOLD for severity when compared to the other groups ${ }^{66}$ In addition, there were $2-3$ participants per group who had an FEV1/FVC ratio of more than 0.7 , and more FVC, while the FEV1 $\%$ was less than $80 \%$, which possibly explains the improvement in lung pathology.

This study was performed in COPD participants because of their high oxidative stress and chronic inflammation, when compared to healthy subjects ${ }^{67,68}$ or those with chronic infection. ${ }^{10}$ Previous evidence found that various inflammatory cytokines, especially TNF- $\propto$, had a higher level in COPD patients. ${ }^{69}$

The effectiveness of product consumption was studied preliminarily by combining star fruit juice with honey because of the industrial commitment under the grant approval from the Research and Researcher for Industries (RRI). Former results on sour-type star fruit showed high Vit C, total phenolic compound and antioxidant activity. ${ }^{47}$ Moreover, the 4-week supplement of sour-type star fruit juice could reduce TNF- $\propto$ and nitric oxide (NO) in elderly people. ${ }^{46}$ Therefore, the possible modification of sweet-type star fruit can be performed as a commercial product, and its efficiency in people was re-evaluated. The antioxidant status in plasma, such as Vit C, TAC and MDA, were evaluated especially as well as the inflammatory cytokine; TNF- $\propto$. All parameters between the groups at the baseline period were not statistically different, except for Vit C levels in the supplement with walking exercise group, which were significantly lower than those in the other groups. When the 4-week period was completed, the Vit $\mathrm{C}$ and TAC levels increased and MDA and TNF- $\propto$ levels decreased significantly in the supplement group. These results of Vit C, MDA and TNF- $\propto$ were in contrast to those in the walking exercise group. 
Pothasak, et al.: Prototype Star Fruit-Honey Product and Effectiveness on Antixidants, Inflammation and Walking Distance in Participants with Stable Chronic Obstructive Pulmonary Disease (COPD)

Table 4: Antioxidant status, tumor-necrotic factor-alpha, 6-minutes walking distance.

\begin{tabular}{|c|c|c|c|c|c|c|c|c|c|c|}
\hline \multirow{2}{*}{ Parameters } & \multicolumn{2}{|c|}{ Control } & \multicolumn{2}{|c|}{ Supplement } & \multicolumn{2}{|c|}{ Exercise } & \multicolumn{2}{|c|}{ Supplement + Exercise } & \multirow[b]{2}{*}{$p^{*}$} & \multirow[b]{2}{*}{$\mathrm{p}^{\#}$} \\
\hline & Before & After & Before & After & Before & After & Before & After & & \\
\hline $\begin{array}{l}\text { Ascorbic acid } \\
(\mu \mathrm{g} / \mathrm{dL})\end{array}$ & $\begin{array}{l}45.4 \pm 1.93 \\
(5.25-6.34)\end{array}$ & $\begin{array}{c}43.60 \pm 1.28 \\
(5.22-7.00)\end{array}$ & $\begin{array}{c}44.15 \pm 1.99 \\
(4.11-6.09)\end{array}$ & $\begin{array}{c}47.15 \pm 1.64 \\
(4.45-7.08)\end{array}$ & $\begin{array}{c}48.90 \pm 2.19 \\
(3.12-5.54)\end{array}$ & $\begin{array}{c}45.92 \pm 0.96 \\
(4.35-6.42)\end{array}$ & $\begin{array}{c}39.00 \pm 2.29 \\
(3.19-6.05)\end{array}$ & $\begin{array}{c}42.26 \pm 2.04 \\
(5.39-6.94)\end{array}$ & 0.032 & 0.218 \\
\hline $\begin{array}{c}\text { TAC }(\mathrm{mmol} \\
\text { Trolox/L) }\end{array}$ & $\begin{array}{c}5.7 \pm 0.12 \\
(5.25-6.34)\end{array}$ & $\begin{array}{l}5.97 \pm 0.18 \\
(5.22-7.00)\end{array}$ & $\begin{array}{c}5.1 \pm 0.14 \\
(4.11-6.09)\end{array}$ & $\begin{array}{l}5.78 \pm 0.15 \\
(4.45-7.08)\end{array}$ & $\begin{array}{l}4.29 \pm 0.23 \\
(3.12-5.54)\end{array}$ & $\begin{array}{l}5.81 \pm 0.24 \\
(4.35-6.42)\end{array}$ & $\begin{array}{l}4.45 \pm 0.20 \\
(3.19-6.05)\end{array}$ & $\begin{array}{l}6.28 \pm 0.13 \\
(5.39-6.94)\end{array}$ & 0.117 & 0.000 \\
\hline $\begin{array}{c}\text { MDA } \\
(\mu \mathrm{mol} / \mathrm{L})\end{array}$ & $\begin{array}{l}4.21 \pm 0.33 \\
(3.06-6.45)\end{array}$ & $\begin{array}{l}4.02 \pm 0.37 \\
(2.65-6.55)\end{array}$ & $\begin{array}{c}3.71 \pm 0.25 \\
(2.44-6.6)\end{array}$ & $\begin{array}{c}2.24 \pm 0.14 \\
(1.47-3.6)\end{array}$ & $\begin{array}{l}3.58 \pm 0.17 \\
(2.96-4.32)\end{array}$ & $\begin{array}{c}3.90 \pm 0.31 \\
(2.52-5.8)\end{array}$ & $\begin{array}{l}4.36 \pm 0.44 \\
(2.49-8.85)\end{array}$ & $\begin{array}{l}2.92 \pm 0.24 \\
(1.31-5.15)\end{array}$ & 0.297 & 0.000 \\
\hline $\begin{array}{c}\text { TNF- } \propto(p g / \\
\mathrm{mL})\end{array}$ & $\begin{array}{c}10.27 \pm 0.52 \\
(4.86-8.88)\end{array}$ & $\begin{array}{c}10.67 \pm 0.56 \\
(5.02-9.01)\end{array}$ & $\begin{array}{l}10.00 \pm 0.34 \\
(4.21-10.17)\end{array}$ & $\begin{array}{c}9.30 \pm 0.32 \\
(5.87-12.86)\end{array}$ & $\begin{array}{c}11.44 \pm 0.72 \\
(5.36-8.83)\end{array}$ & $\begin{array}{c}12.44 \pm 0.72 \\
(5.47-9.59)\end{array}$ & $\begin{array}{c}10.49 \pm 1.37 \\
(3.72-9.1)\end{array}$ & $\begin{array}{c}9.40 \pm 0.35 \\
(7.82-13.33)\end{array}$ & 0.415 & 0.001 \\
\hline 6MWD (m) & $\begin{array}{c}332.1 \pm 12.2 \\
(290-385)\end{array}$ & $\begin{array}{c}351.1 \pm 11.43 \\
(300-400)\end{array}$ & $\begin{array}{c}328.75 \pm 5.74 \\
(200-400)\end{array}$ & $\begin{array}{c}349.7 \pm 20.21 \\
(120-466)\end{array}$ & $\begin{array}{c}330.8 \pm 17.38 \\
(230-375)\end{array}$ & $\begin{array}{c}374.2 \pm 9.41 \\
(332-400)\end{array}$ & $\begin{array}{c}325.8 \pm 11.96 \\
(235-395)\end{array}$ & $\begin{array}{c}376.8 \pm 14.31 \\
(288-510)\end{array}$ & 0.081 & 0.008 \\
\hline
\end{tabular}

Note: $\mathrm{TAC}=$ total antioxidant capacity, $\mathrm{MDA}=$ malondialdehyde, $\mathrm{TNF}=$ tumor necrotic factor, $6 \mathrm{MWD}=6$-minutes walking distance, ${ }^{\star} \mathrm{p}$ value was calculated statistically between the groups before the 4 -week period, and \# p value was calculated statistically between the groups with One-way ANOVA after it.

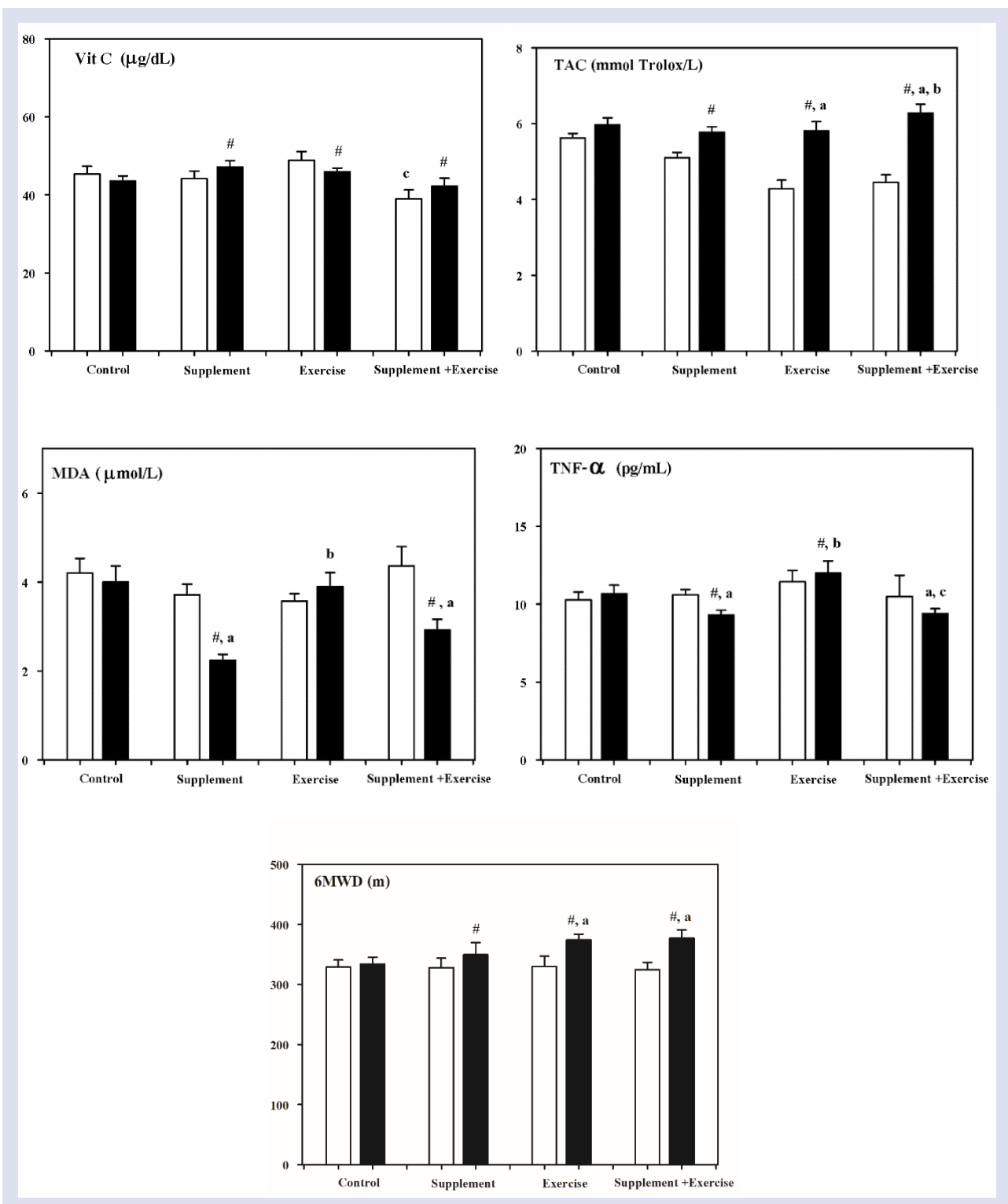

Figure 3: Oxidative Stress (L-ascorbic acid, total antioxidant capacity; TAC, malondialdehyde; MDA), inflammation (tumor necrotic factor (TNF- $\propto$ ), and 6-minutes walking distance (6MWD) between the groups before (white bar) and after (black bar) the 4-week period. P value was analyzed statistically with repeated measurement ANOVA (four groups and twice in each group) and Bonferroni post-hoc analysis. \# $p<0.05$ when compared to before the period within a group, whereas ${ }^{\mathrm{a}} \mathrm{p}<0.05$ when compared to the control group, ${ }^{b} p<0.05$ when compared to the supplement group and ${ }^{c} p<0.05$ when compared to the exercise group in the same period. 
The design of this study was used for comparing results of with or without the walking exercise. A previous study documented that exercise should be included in the pulmonary rehabilitation program for improving physical capacity and health quality in COPD patients, ${ }^{70}$ especially in reducing MDA and improving the total radical-trapping antioxidant parameter (TRAP), after an 8-week conditioning program with cycle ergometer (three times per week). ${ }^{71}$ Unfortunately, the expensive cycle ergometer or treadmill was not available at homes with low-economic status. Home-based walking exercise is an updated protocol that is very simple and suitable for COPD patients who have returned to a sedentary lifestyle at home, ${ }^{33}$ and want to improve their QOL $^{34,3}$ and exercise tolerance. ${ }^{35}$ In addition, the walking program could be combined with exercise training for gaining physical activity in COPD patients. ${ }^{72}$ However, a previous study showed that in the endurance exercise, localized to the leg quadriceps, eleven COPD patients increased their MDA levels and index of oxidative stress, and reduced their vitamin $\mathrm{E}$ level when compared to healthy subjects. ${ }^{73}$ They also failed to raise antioxidant activity. ${ }^{74}$ Although the walking exercise at home potentially benefits physical activity and QOL, the benefits on oxidative stress among COPD patients are also controversial.

The walking exercise protocol in this study recommended a 20-min period, in which patients with moderate dyspnea could improve their exercise capacity and QOL by following a previous study. ${ }^{34}$ Although the TAC status increased significantly after completing 4-weeks of walking exercise, the results also reflected oxidative stress among the COPD participants, with a significant decrease in Vit $\mathrm{C}$ and increase in MDA level. However, the MDA level significantly increased in 21 COPD patients after $3 \mathrm{~h}$ of exercise. ${ }^{75}$ This study proposed that oxidative stress was maintained for the 4 -week period. In addition, the inflammatory cytokine; TNF- $\propto$, significantly increased when 4 -weeks of walking exercise had been completed. The result of inflammation from exercise in this study supported previous evidence of TNF$\propto$ release immediately after and $48 \mathrm{~h}$ post period from continuous moderate walking exercise in COPD patients. ${ }^{76}$ Therefore, the results showed that the walking exercise induced oxidative stress status.

This study compared potential antioxidant activity in the product with or without the walking exercise. A previous study found that application of antioxidant therapy could improve the exercise time and decrease the MDA level in 10 COPD patients. ${ }^{75}$ Various antioxidant compounds such as $\mathrm{N}$-acetyl-L-cysteine and $\mathrm{N}$-acystelyn, erdosteine, fudosteine, ergothioneine, and carbocysteine inhibited lipid peroxidation in COPD patients. ${ }^{77}$ An updated report proposed that diets should have more antioxidant and anti-inflammatory activity, and have an important role in preventing and treating COPD patient. ${ }^{78}$ In addition, an updated study in 2019 showed that oral antioxidant supplementation, which comprised tocopherol, ascorbate, zinc gluconate, and selenomethionine during moderate-intensity exercise training for 28 days, increased muscle strength, serum protein, and plasma antioxidant compounds in COPD patients, when compared to non-antioxidant supplementation during exercise training. ${ }^{37}$ In this study, the product consisted of star fruit juice mixed with honey at a 1:1 ratio by volume, of which the optimized dose could not be summarized for antioxidant activity in the COPD participants. However, a low concentration of Vit $\mathrm{C}$ was identified in the product. Other evidence showed that the honey, produced locally in the Chiang Mai Healthy Product Co., Ltd., had health benefits such as debriding wounds, killing bacteria, penetrating biofilm, lowering wound $\mathrm{pH}$, reducing chronic inflammation and promoting fibroblast infiltration. ${ }^{79}$ Bioactive compounds such as octadecarnoic acid ${ }^{80}$ and oligosaccharides, amino acid, protine, phenolics and flavonoids ${ }^{81}$ are the main ingredients in honey. Therefore, the combination of star fruit juice with honey possibly has antioxidant and anti-inflammatory activities. Results in the supplement group showed an improvement in antioxidant status by significant increases of Vit $\mathrm{C}$ and TAC levels. The data on the significant decrease of MDA and TNF- $\propto$ levels was presented when they were compared with each other before the 4-week period and within the groups or between them and the controls after the 4 -week period. Thus, Vit $\mathrm{C}$ and phenolic compounds in the product are possibly some of many active antioxidant compounds that could reduce lipid peroxidation, as seen in previous evidence. ${ }^{82}$ The results of reducing TNF- $\propto$ in the supplement group could be explained by Vit $C$ activity on the depression and expression of transcription factor NF-Kappa $B,{ }^{83}$ the same as for total phenolic compound. ${ }^{84}$ Unfortunately, the activity on antioxidants and anti-inflammation among the COPD participants could not confirm Vit $\mathrm{C}$ or total phenolic compound as being in the product, as in a previous report on sweet-type star fruit extract. ${ }^{48}$ These activities possibly relate in part to the honey composition in the product because of anti-lipid oxidation activity ${ }^{85}$ and anti-inflammation ${ }^{86}$ as in previous studies. Moreover, an updated study found that total phenolic compound was presented in a variety of honey by the same evaluated Folin-Ciocalteu method used in this study. ${ }^{87}$ This study was consistant with a previous report that showed the efficiency of buckwheat honey, from which total phenolic compound increased plasma antioxidant and reduced capacity among healthy human subjects. ${ }^{88}$ Although this study did not show the total phenolic compound in honey before the manufacturing process with star fruit juice, total phenolic compound in the finished product was identified. The significant difference in Vit C, TAC, MDA and TNF- $\propto$ levels possibly relates to the Vit C and total phenolic compound in the product.

In addition, benefits of the product during walking exercise was costudied. Previous data showed that walking exercise decreased Vit $\mathrm{C}$ and increased MDA as well as TNF- $\propto$, whereas, TAC increased when the 4-week period was completed. The results showed the protective effects of the product during walking exercise, by increases in Vit $\mathrm{C}$ and decreases in MDA and TNF- $\propto$ levels. When comparing all of the parameters in the supplement in the walking exercise group to those in the other groups during the 4-week period, the Vit $C$ level was not statistically different, and the TAC level differed significantly from that

Table 5: Renal function (BUN \& creatinine), Fasting blood sugar (FBS) and Oxalic acid.

\begin{tabular}{|c|c|c|c|c|c|c|c|c|c|c|}
\hline \multirow{2}{*}{ Parameters } & \multicolumn{2}{|c|}{ Control } & \multicolumn{2}{|c|}{ Supplement } & \multicolumn{2}{|c|}{ Exercise } & \multicolumn{2}{|c|}{ Supplement + Exercise } & \multirow[b]{2}{*}{$p^{*}$} & \multirow[b]{2}{*}{$\mathrm{p}^{\#}$} \\
\hline & Before & After & Before & After & Before & After & Before & After & & \\
\hline $\begin{array}{c}\text { BUN } \\
(\mathrm{mg} / \mathrm{dL})\end{array}$ & $\begin{array}{c}12.29 \pm 0.88 \\
(9.5-18.0)\end{array}$ & $\begin{array}{c}12.98 \pm 0.71 \\
(10.4-18.0)\end{array}$ & $\begin{array}{c}12.85 \pm 0.71 \\
(7.7-18.3)\end{array}$ & $\begin{array}{c}14.22 \pm 1.29 \\
(8.2-36.1)\end{array}$ & $\begin{array}{c}12.74 \pm 1.27 \\
(6.8-18.5)\end{array}$ & $\begin{array}{c}12.10 \pm 0.99 \\
(7.3-16.2)\end{array}$ & $\begin{array}{c}14.38 \pm 0.91 \\
(9.9-20.2)\end{array}$ & $\begin{array}{c}14.42 \pm 1.08 \\
(10-22.2)\end{array}$ & 0.414 & 0.538 \\
\hline $\begin{array}{l}\text { Creatinine } \\
(\mathrm{mg} / \mathrm{dL})\end{array}$ & $\begin{array}{l}0.93 \pm 0.03 \\
(0.77-1.11)\end{array}$ & $\begin{array}{l}0.93 \pm 0.03 \\
(0.81-1.10)\end{array}$ & $\begin{array}{l}0.89 \pm 0.03 \\
(0.61-1.11)\end{array}$ & $\begin{array}{l}1.00 \pm 0.08 \\
(0.64-2.44)\end{array}$ & $\begin{array}{l}0.88 \pm 0.03 \\
(0.74-1.03)\end{array}$ & $\begin{array}{l}0.85 \pm 0.03 \\
(0.74-1.03)\end{array}$ & $\begin{array}{c}0.88 \pm 0.04 \\
(0.64-1.4)\end{array}$ & $\begin{array}{l}0.89 \pm 0.05 \\
(0.64-1.40)\end{array}$ & 0.801 & 0.467 \\
\hline $\begin{array}{c}\text { FBS } \\
(\mathrm{mg} / \mathrm{dL})\end{array}$ & $\begin{array}{c}93.7 \pm 1.9 \\
(82-99)\end{array}$ & $\begin{array}{c}91.6 \pm 2.3 \\
(76-99)\end{array}$ & $\begin{array}{c}98.2 \pm 2.4 \\
(75-119)\end{array}$ & $\begin{array}{c}110.1 \pm 3.3 \\
(75-133)\end{array}$ & $\begin{array}{c}96.8 \pm 2.4 \\
(78-101)\end{array}$ & $\begin{array}{c}90.2 \pm 1.4 \\
(86-98)\end{array}$ & $\begin{array}{c}90.1 \pm 4.4 \\
(73-123)\end{array}$ & $\begin{array}{c}98.4 \pm 4.4 \\
(73-121)\end{array}$ & 1.49 & 0.611 \\
\hline $\begin{array}{c}\text { Oxalic acid } \\
(\mu \mathrm{g} / \mathrm{mL})\end{array}$ & ND & ND & ND & $\begin{array}{l}2.56 \pm 0.14 \\
(0.53-2.66)\end{array}$ & ND & ND & ND & $\begin{array}{l}1.52 \pm 0.14 \\
(0.25-2.11)\end{array}$ & - & 0.78 \\
\hline
\end{tabular}

Note: BUN = blood urea nitrogen, FBS = fasting blood sugar; ND = non-detectable, * p value was calculated statistically between the groups before the 4-week period, and \# p value was calculated statistically between the groups with One-way ANOVA after it. 
in the control and supplement groups. Whereas, the MDA level showed a statistical difference from that in the control group. In addition, the TNF- $\propto$ differed significantly between the control and exercise groups. Therefore, these results showed the benefits of the product in walking exercise-induced oxidative stress among the COPD participants in this study.

The results from the $6 \mathrm{MWD}$ showed a significant increase in physical function in all of the groups when compared to before the study. Data showed slightly longer distance in the supplement with walking exercise group than in the exercise and supplement groups during the 4-week period, but there was no significant difference between the groups, except for the control group. Therefore, effects of the significant increase in physical function from the 6MWD in the supplement with walking exercise group could not be summarized from either the product or walking exercise. This result was consistent with a previous updated study, in that 28-days of supplemented nutrient consisted of tocopherol $(30 \mathrm{mg} /$ day $)$, Vit C $(180 \mathrm{mg} /$ day $)$, zinc gluconate $(15 \mathrm{mg} /$ day) and serenomethionine (50 g/day) during moderated-intensity exercise. The result showed no improvement in antioxidant status or muscle strength among the COPD patients. Whereas, the walking exercise or supplement group improved significantly in muscle strength and antioxidant status. ${ }^{37}$ However, results of the combined product in the walking exercise group could not conclude as to whether the low level of Vit C in the product and total phenolic compound affected TAC or the $6 \mathrm{MWD}$. A previous study found that 3 grams of Vit $\mathrm{C}$ supplement could prevent muscle damage and increase exercise time. ${ }^{89}$ Although a previous study found a significant change in the walking exercise in COPD patients, ${ }^{90}$ the minimally clinical improvement of $54-80 \mathrm{~m}$ in the 6MWD has been proposed ${ }^{91}$ and found in the supplement with walking exercise group. Thus, the combined supplement with walking exercise possibly affects walking tolerance.

Finally, this study confirmed the adverse effects from the star fruit juice with honey product. Although blood urea nitrogen (BUN) and creatinine levels slightly increased in the supplement and supplement with walking exercise groups, when comparing between before, during and after the study period, there was no significant difference within normal references $(5-20 \mathrm{mg} / \mathrm{dL}$ of BUN and $0.6-1.5 \mathrm{mg} / \mathrm{dL}$ of creatinine).${ }^{92}$ Moreover, the high glucose level in star fruit juice with honey also should be realized in cases of diabetes or glucose-induced diabetes. Nutritional facts from the United States Drug Association (USDA) showed 5.3 grams of glucose in 132 grams of cubed star fruit. ${ }^{93,94}$ Thus, the FBS level was rechecked and results showed a slight increase without statistical changes when the 4 -week period was completed. Although the honey was mixed with star fruit juice at $50 \%$ by volume, the FBS level was not statistically different. This result is supported by a previous study of diabetic patients with no statistical difference from 8 weeks of consumption. ${ }^{95}$ In addition, oxalic acid must be of concern and limited to a safe dose range of $0.10-0.28 \mathrm{~g} / \mathrm{mL}$ plasma in humans. ${ }^{96}$ This study found oxalic acid in the supplement $(2.56 \pm 0.14 \mu \mathrm{g} / \mathrm{mL})$ and supplement with walking exercise groups $(1.52 \pm 0.14 \mu \mathrm{g} / \mathrm{mL})$.

There were no symptoms among the participants who consumed the product. In addition, the interesting neurotoxic substance in star fruit; caramboxin, is a new phenylalanine-like molecule that is similar to an agonist of glutamateric receptors with convulsant and neurodegenerative properties. A previous report found that consumption of pure highdose star fruit juice at $1,500 \mathrm{~mL}$ showed adversed effects such as hiccups, vomitng, insomnia and mental confusion..$^{97}$ Unfortunately, this study did not evaluate caramboxin in the product, but symptomatic results were evaluated by weekly interviews during the 4 weeks of supplement consumption, and no symptoms such as vomiting, confusion, vertigo, numbness or hiccups were found from oxalic acid or caramboxin toxicity in the central nervous system. ${ }^{98,99}$ This study could not confirm whether there is biological toxicity, therefore, more study and confirmation are needed, especially on longer consumption, although the composition of star fruit juice in the product was very low. Furthermore, all of the participants stated that the taste, product appearance and color were perfect.

\section{CONCLUSION}

This study showed that a new product of sweet-type star fruit mixed with honey was safe and could be developed as a commercial product under the FDA of Thailand. Vit $\mathrm{C}$ and total phenolic compound are two of many bioactive compounds that show health benefits in antioxidants and anti-inflammation, as well as walking distance for COPD patients.

\section{LIMITATION AND SUGGESTION}

This study was a preliminary work among COPD participants, but the sample size in the control group was lower, and age in the walking exercise group younger, when compared to the other groups. These factors may affect the results in this study, thus future research is needed for confirmation. In addition, results of different product preparations, longer period of consumption and health benefits for different participants such as healthy people, or other diseases, should be studied.

\section{ACKNOWLEDGEMENTS}

This study was supported partially by a grant from the Research and Researchers for Industries (RRI) (Contact Number: MSD 61I01100) under the Thailand Research Fund (TRF) of Thailand. Furthermore, Thanks go to all of the participants and co-researchers at Baan Tor district, San Sai, Chaing Mai province, Thailand for their great cooperation during this study.

\section{CONFLICTS OF INTEREST}

All of the authors and the industrial partner (Chiang Mai Healthy Product Co., Ltd., Chaing Mai, Thailand) claimed no conflicts of interests in this study.

\section{REFERENCES}

1. Rabe KF, Hurd S, Anzueto A, Barnes PJ, Buist SA, Calverly P, et al. Global strategy for the diagnosis, management, and prevention of chronic obstructive pulmonary disease: GOLD executive summary. Am J Respir Crit Care Med. 2007; 176(6): 532-55.

2. Pothirat $C$, Chaiwong W, Phetsuk P, Pisalthanapuna S, Chetsadaphan N, Inchai J. A comparative study of COPD burden between urbans vs rural communities in northern Thailand. Int J Chron Obstruct Pulmon Dis. 2015; 10: 1035-42.doi: 10.2147/COPD/S82303. eCollection 2015.

3. Hill K. Supervised walking training improves health-related quality of life and exercise tolerance in people with chronic obstructive pulmonary disease. $J$ Physiother. 2016; 62: 50. doi: 10.1016/j.jphys.2015. 10.002. Epub 2015 Dec 11.

4. Johns DP, Walters JA, Walters EH. Diagnosis and early detection of COPD using spirometry. J Thorac Dis. 2014; 6(11), 1557-69. doi: 10.3978/j.issn.20721439.2014. 08.18.

5. Rebordosa C, Plana E, Aguado J, Thomas S, Garcia-Gil E, Perez-Gutthann S, Castellsague J. GOLD assessment of COPD severity in the Clinical Practice Research Datalink (CPRD). Pharmacoepidemiol Drug Saf. 2018; 28(2), 126-33. doi: 10.1002/pds.4448. Epub 2018 May 8.

6. Marginean C, Popescu MS, Vladaia M, Tudorascu D, Pirvu DC, Petrescu F. Involvement of oxidative stress in COPD. Curr Health Sci J. 2018; 44(1): 48-55. doi: 10.12865/CHSJ.44.01.08.

7. Elmasry SA, Al-Azzawi MA, Ghoneim AH, Nasr MY, AboZaid, MMN. Role of oxidant-antioxidant imbalance in the pathogenesis of chronic obstructive pulmonary disease. Egyp J Chest Dis Tuberc. 2015; 64(4): 813-20.

8. Ahmad A, Shameem M, Husain Q. Altered oxidant-antioxidant levels in the disease prognosis of chronic obstructive pulmonary disease. Int J Tuberc Lung Dis. 2013; 17: 1104-9. doi: 10.5588/ijtld.12.0512.

9. Barreiro E. Protein carbonylation and muscle function in COPD and other conditions. Mass Spectrom Rev. 2014; 33: 219-36.

10. Kunnumakkara AB, Sailo BL, Banik K, Harsha C, Prasad S, Gupta SC, Bharti AC, Aggarwal BB. Chronic disease, inflammation, and species: how are they linked?. J Trans Med. 2018; 16(1): 14. doi:10.1186/s12967-018-1381-2. 
Pothasak, et al:: Prototype Star Fruit-Honey Product and Effectiveness on Antixidants, Inflammation and Walking Distance in Participants with Stable Chronic Obstructive Pulmonary Disease (COPD)

11. Tomita K, Barnes PJ, Adcock IM. The effect of oxidative stress on histone acetylation and IL-8 release. Biochem Biophys Res Commun. 2003; 301(2): 572-27.

12. Shaw JG, Vaughan A, Dent AG, O'Hare PE, Goh F, Bowman RV, Fong KM, Yang IA. Biomarkers of progression of chronic obstructive pulmonary disease (COPD). JThorac Dis. 2016; 6(11): 1532-47. doi: 10.3978/j.issn.2072-1439.2014. 11.33.

13. Farne HA, Cates CJ. Long-acting beta2-agonist in addition to tiotropium versus either tiotropium or long-acting beta2-agonist alone for chronic obstructive pulmonary disease. Cochrane Database Syst Rev. 2015; 22(10): CD008989. doi: 10.1002/14651858. CD. 008989. pub3.

14. Vogelmeier CF, Criner GJ, Martinez FJ, Anzueto A, Barnes PJ, Bourbeau J, et al. Global Strategy for the Diagnosis, Management, and Prevention of Chronic Obstructive Lung Disease 2017 Report. GOLD Executive Summary. Amer J Respir Crit Care Med. 2017; 195(5): 557-82. doi: 10.1164/rccm. 201701-0218PP.

15. Voelkel NF, Tuder R. COPD: exacerbation. Chest. 2000; 117(5 Suppl): 376S-379S.

16. de Jong YP, Uil SM, Grotjohan HP, Postma DS, Kerstjens HA, van den Berg JW. Oral or IV prednisolone in the treatment of COPD exacerbations: a randomized, controlled, double-blind study. Chest. 2007; 132: 1741-7. Epub 2007 Jul 23.

17. Verhoeven G, Hegmans J, Mulder P, Bogaard J, Hoogsteden H, Prins J. Effects of fluticasone propionate in COPD patients with bronchial hyperresponsiveness. Thorax. 2005; 57(8): 694-700.

18. Wang Z, Yang C, Yang X. Efficacy of salmeterol and formoterol combination treatment in mice with chronic obstructive pulmonary disease. Exper Ther Med. 2018; 15(2): 1538-45. doi: 10.3892/etm.2017.5562. Epub 2017 Nov 24.

19. Miravitlless M, Anzueto A. Chronic Respiratory Infection in Patients with Chronic Obstructive Pulmonary Disease: What is the Role of Antibiotic. International journal of molecular sciences. 2017; 18(7): pii: E1344. doi:10.3390/ ijms1807 1344.

20. Anthonisen NR, Connett JE, Murray RP. Smoking and lung function of Lung Health Study participants after 11 years. Amer J Respir Crit Care Med. 2002; 166(5): 675-9.

21. Oancea C, Fira-Mladinescu O, Timar B, Tudorache V. Impact of medical education program on COPD patients: a cohort prospective study. Wien Klin Wochenschr. 2015; 127: 388-93

22. Brill SE, Wedzicha JA. Oxygen therapy in acute exacerbation of chronic obstructive pulmonary disease. Inter J Chron Obstruc Pulmon Dis. 2014; 9 : 1241-52. doi: 10.2147/COPD.S41476.eCollection 2014.

23. Vogiatzis I, Rochester CL, Spruit MA, Troosters T, Clini EM. American Thoracic Society/European Respiratory Society Task Force on Policy in Pulmonary Rehabilitation. Increasing implementation and delivery of pulmonary rehabilitation: key messages from the new ATS/ERS policy statement. Euro Respir J. 2005; 47(5), 1336-41. doi: 10.1183/13993003.02151-2015.

24. Ries AL, Bauldoff GS, Carlin BW, Casaburi R, Emery CF, Mahler DA, et al. Pulmonary rehabilitation; Joint ACCP/AACVPR Evidence-based clinical practice guidelines. Chest. 2007; 213(5): 4S-42S.

25. Mikelsons $\mathrm{C}$. The role of physiotherapy in the management of COPD. Respiratory medicine, COPD update 2008; 4(1): 2-7.

26. Gloecki R, Marinov B, Pitta F. Practical recommendations for exercise training in patients with COPD. Eur Respir Rev. 2013; 22(128): 178-86. doi: 10.1183/09059180. 00000513.

27. Casaburi R, Porszasz J, Burns MR, Carithers ER, Chang RS, Cooper CB. Physiologic benefits of exercise training in rehabilitation of patients with severe chronic obstructive pulmonary disease. Amer J Respir Crit Med. 1997; 155(5): 1541-51.

28. Powers SK, Jackson MJ. Exercise-induced oxidative stress; Cellular mechanisms and impact on muscle force production. Physiol Rev. 2008; 88(4): 1243-76. doi: 10.1152/physrv.00031.2007.

29. Atashak S, Azizbeigi K, Azarbayjani MA, Stannard S, Dehghan F, Soori R. Changes of stress proteins and oxidative stress indices with progressive exercise training in elderly men. Sci Sports. 2017; 32(3): 152-9.

30. Koubaa A, Triki M, Trabelsi H, Baati H, Sahnoun Z, Hakim A. The effect of a 12 week moderate intensity interval training program on the antioxidant defense capability and lipid profile in men smoking cigarettes or hookah: a cohort study. Sci World J. 2015; 639369. doi:10.1155/2015 /639369. Epub 2015 Jan 14.

31. Samjoo IA, Safdar A, Hamadeh MJ, Raha S, Tarnopolsky MA. The effect of endurance exercise on both skeletal muscle and systemic oxidative stress in previously sedentary obese men. Nutr Diabet. 2013; 3: e88. doi: 10.1038/ nutd.2013.30.

32. Koechlin C, Couillard A, Cristol JP, Chanez P, Hayot M, Le Gallais D, Prefaut C Does systemic inflammation trigger local exercise -induced oxidative stress in COPD? Eur Respir J. 2004; 23: 538-44.

33. Bender BG, Depew A, Emmett A, Goelz K, Make B, Sharma S, Underwood J, Stempel D. A Patient-Centered Walking Program in COPD. COPD. 2016; 3(4): 769-77. doi: 10.15326/jcopdf.3.4.2016.0142.
34. Wootton SL, Nq LW, McKeough ZJ, Jenkins S, Hill K, Eastwood PR, et al. Ground-bases walking training improves quality of life and exercise capacity in COPD. Eur Respir J. 2014; 44(4): 885-94. doi: 10.1183/09031936.00078014. Epub 2014 Aug 19

35. Liu WT, Wang CH, Lin HC, Lin SM, Lee KY, Lo YL, et al. Efficacy of a cell phone-based exercise programme for COPD. Eur Respir J. 2008; 32(3): 651-9. doi:10.1183/09031936.00104407. Epub 2008 May 28.

36. van Helvoort HAC, Heijdra YF de Boer RCC, Swinkels A, Thijs HMH, Dekhuijzen PNR. Six-minute walking induced systemic inflammation and oxidative stess in muscle-wasted COPD patients. Chest. 2007; 131(2): 439-45.

37. Gouzi F, Maury J, Heraud N, Molinari N, Bertet H, Ayoub B, et al. Additional Effects of Nutritional Antioxidant Supplementation on Peripheral Muscle during Pulmonary Rehabilitation in COPD Patietns: A Randomized Controlled Trial. Oxid Med Cell Longev. 2019; 5496346. doi: 10.1155/2019/5496346. eCollection 2019.

38. Kwon J, Suzuki T, Yoshida H, Kim H, Yoshida Y, Iwasa H. Concomitant lower serum albumin and vitamin D levels are associated with decreased objective physical performance among Japanese community-dwelling elderly. Gerontology. 2007; 53(5): 322-8.Epub 2007 May 29.

39. Suzuki T, Kwon J, Kim H, Shimada $H$, Yoshida $Y$, Iwasa $H$, et al. Low serum 25-hydroxyvitamin $D$ levels associated with falls among Japanese communitydwelling elderly. J Bone Miner Resear. 2008; 23(8): 1309-1317. doi: 10.1359 jbmr.080328.

40. Rokitzki L, Logemann E, Sagredos AN, Murphy M, Wetzel-Roth W, Keul J. Lipid peroxidation and antioxidative vitamins under extreme endurances stress. Acta Physiol Scandinavica. 1994; 151(2): 149-58.

41. McGinley $C$, Shafat A, Donnelly AE. Does antioxidant vitamin supplement-ation protect against muscle damage? Sports Med. 2009; 39(12): 1011-1132. doi 10.2165/ 11317890-000000000-00000.

42. Traber MG, Stevens JF. Vitamins $C$ and $E$ : beneficial effects from mechanistic perspective. Free Rad Biol Med. 2011; 51(5): 1000-3. doi: 10.1016/j. freeradbiomed. 2011. 05.017. Epub 2011 May 25.

43. Ferrari CK. Functional foods and physical activities in health promotion of aging people. Maturitas. 2007; 58(4): 327-39. Epub 2007 Nov 5.

44. Manda H, Vyas K, Pandya A, Singhal G. A completed review on: Averrhoa carambola. World J Pharm Pharma Ssciences. 2012; 1(1): 17-33.

45. Dasgupta P, Chakraborty P, Bala NN. Averrhoa carambola: an updated review. Inter J Pharm Resear Rev. 2013; 2: 54-63.

46. Leelarungrayub J, Laskin JJ, Bloomer RJ, Pinkaew D. Consumption of star fruit juice on pro-inflammatory markers and walking distance in the community dwelling elderly. Arch Gerontol Geriatr. 2016; 64: 6-12. doi: 10.1016/j. archger.2015.12.001. Epub 2015 Dec 2. (B).

47. Leelarungrayub J, Yankai A, Puntumetakul R, Laskin JJ, Bloomer RJ. A preliminary study on the effect of star fruit consumption on antioxidant and lipid status in elderly Thai individuals. Clin Interv Aging. 2016; 11: 1183-92. doi: 10.2147/CIA.S110718. eCollection 2016.

48. Pothasak Y, Singhatong, S, Natakankitkul, Dechsupa N, Wanachantararak $\mathrm{P}$, Dechthummarong $\mathrm{C}$, Leelarungrayub J. Active compounds, free radicals scavenging and tumor-necrotic factor (TNF- $\propto$ ) inhibitory activities of star fruitsweet type (Averrhoa carambola L.) in vitro. J Assoc Med Sci. 2020; 53(1): $19-28$.

49. Furusawa N. Rapid high-performance liquid chromatographic identification quantification of total vitamin $C$ in fruit drinks. Food control. 2001; 12(1): 27-29.

50. Singleton VL, Rossi JA Jr. Colorimetry of total phenolics with phosphomolybdicphosphorungstic acid reagents. Amer J Enol Vitcult. 1965; 16: 144-58.

51. Wilson CW, Shaw PE, Knight RJ. Analysis of Oxalic Acid in Carambola (Averrhoa carmpbola L.) and Spinach by High-Performace Liquid Chromatography. J Agricul Food Chem. 1982; 30: 1106-8.

52. Pirabbasi E, Shahar S, Manaf ZA, Rajab NF, Manap RA. Efficacy of Ascorbic Acid (Vitamin C) and /N-Acetylcysteine (NAC) Supplementation on Nutritional and Antioxidant Status of Male Chronic Obstructive Pulmonary Disease (COPD) Patients. J Nutr Sci Vitaminol. 2016; 62(1): 54-61. doi:10.3177/jnsv.62.54.

53. Re R, Pellegrini N, Proteggente A, Pannala A, Yand M, Rice-Evans C. Antioxidant activity applying an improved ABTS radical cation decolorization assay. Free Radic Biol Med. 1999; 26(9-10): 1231-1237.

54. Chirico S. High-performance liquid chromatograph-based thiobarbituric acid tests. Methods Enzymol. 1991; 233: 314-8.

55. ATS Committee on Proficiency Standards for Clinical Pulmonary Function Laboratories. ATS statement: guidelines of the six-minute walk test. Amer J Respir Crit Care Med. 2002; 166(1): 111-7.

56. ACSM's Guidelines for exercise testing and prescription. J Can Chiropr Assoc. 2014; 58(3): 328.

57. AOAC. Official Methods of Analysis. Association of Association Official Analytical Chemists, Washington DC. 2010.

58. Compendium of methods for food anlaysis/cDepartment of Medical Sciences and National Bureau of Agriculture Commodity and Food Standards. The $1^{\text {st }}$ edition. 2003. 
Pothasak, et al.: Prototype Star Fruit-Honey Product and Effectiveness on Antixidants, Inflammation and Walking Distance in Participants with Stable Chronic Obstructive Pulmonary Disease (COPD)

59. Kaczmarek M, Avery SV, Singleton I. Microbes associated with fresh produce: sources, types and methods to reduce spoilage and contamination. Advan App Microbiol. 2019; 107: 29-82. doi: 10.1016/bs.aambs.2019.02.001. Epyb 2019 Mar 13.

60. Borel NNM, Foba-Tendo J, Yufanyi DM, Etape EP, Eko JN, Ngolui LJ. Averrhoa carambola; A Renewable Source of Oxalic Acid for the Facile and Green Synthesis of Divalent Metal ( $\mathrm{Fe}, \mathrm{Co}, \mathrm{Ni}, \mathrm{Zn}$, and $\mathrm{Cu}$ ) Oxalates and Oxide Nanoparticles. J Appl Chem. 2014; Article ID 767695.

61. Noonan SC, Savage GP. Oxalate content of foods and its effect on humans. Asia Pac J Clin Nutr. 1999; 8(1): 64-74.

62. Hanson SF, Frankos VH, Thompson WO. Bioavailability of oxalic acid from spinach, sugar beef fiber and a solution of sodium oxalate consumed by female volunteers. Food Chem Toxicol. 1989; 27: 181-4.

63. Fassett DW, Oxalates. In: Toxicants occurring naturally in foods, $2^{\text {nd }}$ edtion. Washington. National academy of sciences. 1973; 346-62

64. Hughes J, Norman RW. Diet and calcium stones. Can Med Assoc J. 1992; 146 137-43.

65. Candermir I, Ergun P, Kaymaz D, Tasdemir F, Egsel N. The Comparison of Clinical Variables in Two Classifications; GOLD 2017 Combined Assessment and Spirometric Stage of Chronic Obstructive Pulmonary Disease. Tuberc Respir Dis. 2018; 81(4): 281-8. doi: 10.4046/trd.2017.0114. Epub 2018 Mar 7.

66. Lee JS, Rosengart MR, Kondragunta V, Zhang Y, McMurray J, Branch RA, et al Inverse association of plasma IL-13 and inflammatory chemokines with lung function impairment in stable COPD: a cross-sectional cohort study. Respir Res. 2007; 8: 64. doi: 10.1186/1465-9921-8-64.

67. Singh S, Verma SK, Kumar S, Ahmad MK, Nischal A, Singh SK, et al. Evaluation of Oxidative Stress and Antioxidant Status in Chronic Obstructive Pulmonary Disease. Scandinavian J Immunol. 2017; 85(2): 130-7. doi:10.1111/sji.12498.

68. Yao Y, Zhou J, Diao X, Wang S. Association between tumor necrosis factorand chronic obstructive pulmonary disease: a systematic review and meta-analysis. Ther Adv Respir Dis. 2019; 13: 1753466619866096. doi: 10.1177/1753466619866096.

69. Spruit MA, Burtin C, De Boever P, Langer D, Vogiatzis I, Wouters EFM, et al. COPD and exercise: dose it make a difference?. Breathe (Sheff). 2016; 12(2): e38-e49. doi: 10.1183/20734735.003916.

70. Pinho RA, Chiesa S, Mezzomo KM, Andrades ME, Bonatto F, Gelain D, et al. Oxidative stress in chronic obstructive pulmonary disease patients submitted to a rehabilitation program. Respir Med. 2007; 101(8): 1830-5.

71. de Roos P, Lucas C, Strijbos JH, Trijffel EV. Effectiveness of a combined exercise training and home-based walking programme on physical activity compared with standard medical care in moderate COPD: a randomized controlled trial. Physiotherapy. 2018; 104(1): 116-121. doi: 10.1016/j.physiol.2016.08.005. Epub 2017 Jul 14.

72. Couillard A, Koechlin C, Cristol JP, Varray A, Prefaut C. Evidence of local exercise-induced systemic oxidative stress in chronic obstructive pulmonary disease patients. Eur Respir J. 2002; 20(5): 1123-9.

73. Couillard A, Maltais F, Saey D, Debigare R, Michaud A, Koechlin C, et al. Exerciseinduced quadriceps oxidative stress and peripheral muscle dysfunction in patients with chronic obstructive pulmonary disease. Amer J Respir Crit Care Med. 2003; 167(12): 1664-9.

74. Agacdiken A, Basyigit I, Ozden M, Yildiz F, Ural D, Maral H, et al. The effects of antioxidants on exercise-induced lipid peroxidation in patients with COPD. Respirology. 2004; 9(1): 38-42.

75. Brown M, McClean CM, Davison GW, Brown JCW, Murphy MH. The acute effects of walking exercise intensity on systemic cytokines and oxidative stress. Eur J Appl Physiol. 2018; 118(10): 2111-20.

76. Rahman I. Pharmacological antioxidant strategies as therapeutic interventions for COPD. Biochim Biophys Acta. 2012; 1822(5): 714-28. doi: 10.1016/j.bbadis 2011.11.004. Epub 2011 Nov 9.

77. Scoditti E, Massaro M, Garbarino S, Toraldo DM. Role of diet in chronic obstructive pulmonary disease prevention and treatment. Nutrients. 2019; 11(6): 1357. doi: 10.3390/nu11061357.
78. Minden-Birkenmaier BA, Bowlin GL. Honey-based templates in wound healing and tissue engineering. Bioengineering (Basel). 2018; 5(2): pii: E46. doi:10.3390/ bioengineering 5020046 .

79. Neamatallah T, El-Shitany NA, Abbas AT, Ali SS, Eid BG. Honey protects against cisplatin-induced hepatic and renal toxicity through inhibition of NFkB-mediated COX-2 expression and the oxidative stress dependent BAX-Bcl-2 caspase-3 apoptotic pathway. Food Funct. 2018; 9(7): 3743-54. doi: 10.1039/ c8fo00653a.

80. Wang J, Li QX. Chemical composition, characterization, and differentiation of honey botanical and geographical origins. Adv Food Nutr Res. 2011; 62: 89-137. doi:10.1016/B978-0-12-385989-1.00003-X.

81. Chen ZH, Zhou B, Yang L, Yang L, Wu LM, Liu ZL. Antioxidant activity of green tea polyphenols against lipid peroxidation initiated by lipid-soluble radicals in micelles. Journal of the chemical society, Perkin Transactions 2. 2001; 9: 1835-9.

82. Carcamo JM, Pedraza A, Borguez-Ojeda O, Golde DW. Vitamin C suppresses TNF alpha-induced NF kappa B activation by inhibiting I kappa B alpha phosphorylation. Biochemistry. 2002; 41(43): 12995-3002.

83. Acero N, Munoz-Mingarro D. Effect of tumor necrosis factor- $\propto$ production and antioxidant ability of black alder, as factors related to its anti-inflammatory properties. J Med Food. 2012; 15(6): 542-8. doi:10.1089/jmf.2011.0281. Epub 2012 Mar 16.

84. McKibben J, Engeseth NJ. Honey as a protective agent aginst lipid oxidation in groud Turkey. J Agricul Food Chem. 2002; 50(3): 592-5. doi: 10.1021/jf010820a.

85. Mandal MD, Mandal S. Honey: its medicinal propertry and antibacterial activity. Asian Pac J Trop Biomed. 2011; 1(2): 154-60. doi: 10.1016/S2221-1691(11)60016-6.

86. Dzugan M, Tomczyk M, Sowa P, Grabek-Lejko D. Antioxidant activity as biomarker of honey variety. Molecules. 2018; 23(8): 2069. doi: 10.3390/ molecules 23082069.

87. Schramm DD, Karim M, Schrader HR, Holt RR, Cardetti M, Keen CL. Honey with high levels of antioxidant can provide protection to healthy human subjects. $J$ Agric Food Chem. 2003; 51(6): 1732-5. doi: 10.1021/jf025928k.

88. Bryer SC, Goldfarb AH. Effect of high dose vitamin $\mathrm{C}$ supplementation on muscle soreness, damage, function, and oxidative stress to eccentric exercise. Inter J Sport Nutr Exer Metabol. 2006; 16(3): 270-80.

89. Chandrasekaran B, Reddy KC. Six-minute walk test as a guide for walking prescription for patients with chronic obstructive pulmonary diseases. Indian Respir Care. 2018; 7(2): 73-6.

90. Wise RA, Brown CD. Minimal clinically improvement differences in the sixminute walk test and the incremental shuttle walking test. COPD. 2005; 2(1): 125-9.

91. Hosten AO. BUN and Creatinine, In: Walker HK, Hall WD, Hurst JW, editors. Clinical Methods: The History, Physical, and Laboratory Examinations. 3 rd edition. Boston: Butterworths. 1990.

92. U.S. Department of Argiculture. Food Data Central. Carambola (starfruit), raw. Published April 1, 2019.

93. USDA Database. Carambola (Star fruit), raw. National Nutrient Database for Standard Reference Release 28. United States Department of Agriculture. Agriculture Research Center, USA Government. White House. 2016.

94. Bahrami M, Ataie-Jafari A, Hosseini S, Foruzanfar MH, Rahmani M, Pajouh M. Effects of natural honey consumption in diabetic patients: An 8-week randomized clinical trial. Inter J Food Sci Nutr. 2009; 60(7): 618-26. doi: 10.3109/09637480801990389.

95. Zarembski PM, Hodgkinson A. Plasma oxalic acid and calcium levels in oxalate poisoning. J Clin Pathol. 1967; 20(3): 283-285.

96. Neto MM, Gilva GE, Costa RS, Vieira Neto OM, Garcia-Cairasco N, Lopes NP et al. Star fruit: simultaneous neurotoxic and nephrotoxic effects in people with previously normal function. NDT Puls. 2009; 2(6): 485-488.

97. Aranguren C, Vergara C, Rosselli D. Toxicity of star fruit (Averrhoa carambola) in renal patients: a systemic review of the literature. Saudi J Kidney Dis Transpl. 2017; 28: 709-15.

98. Garcia-Cairasco N, Moyses-Neto M, Del Vecchio F, et al. Elucidating the neurotoxicity of the star fruit. Angewandte Chemie International Edition in English. 2013; 52: 13067-70. 


\section{GRAPHICAL ABSTRACT}
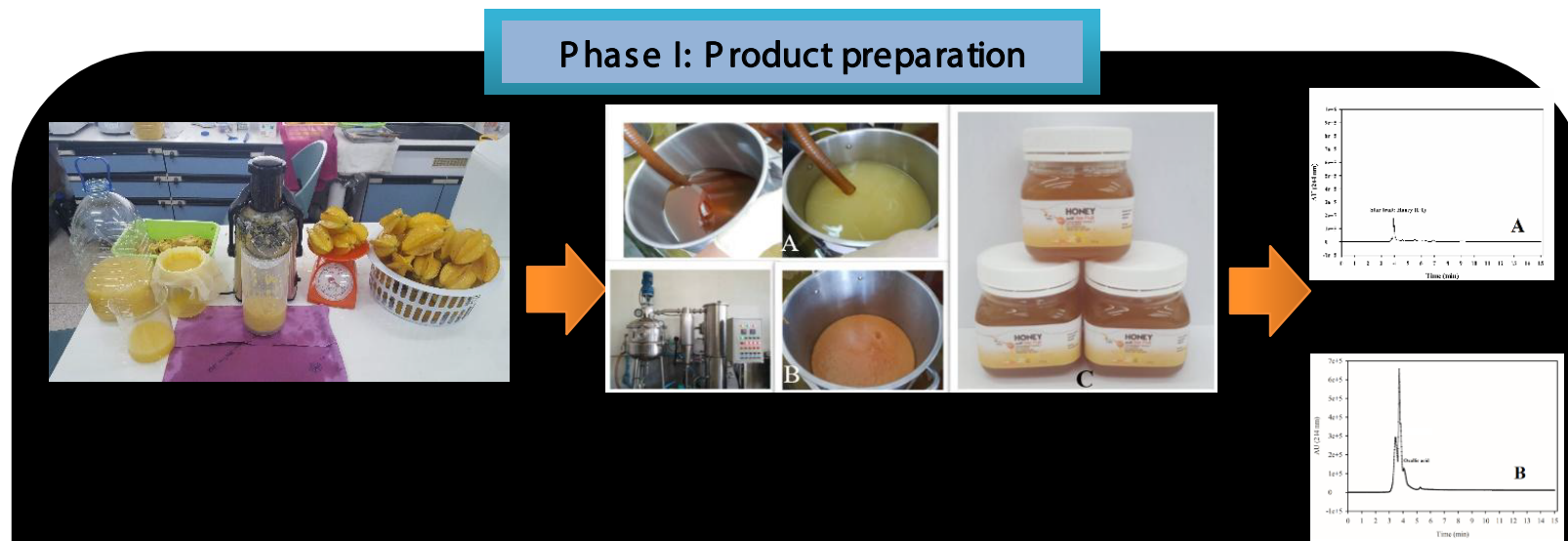

Chemicals and Microbial analys is

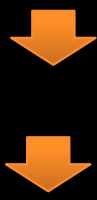

\section{Vit $C$ and Oxalic acid analys is}

Thai FDA serial number: อย.50-1-02237-2-0122

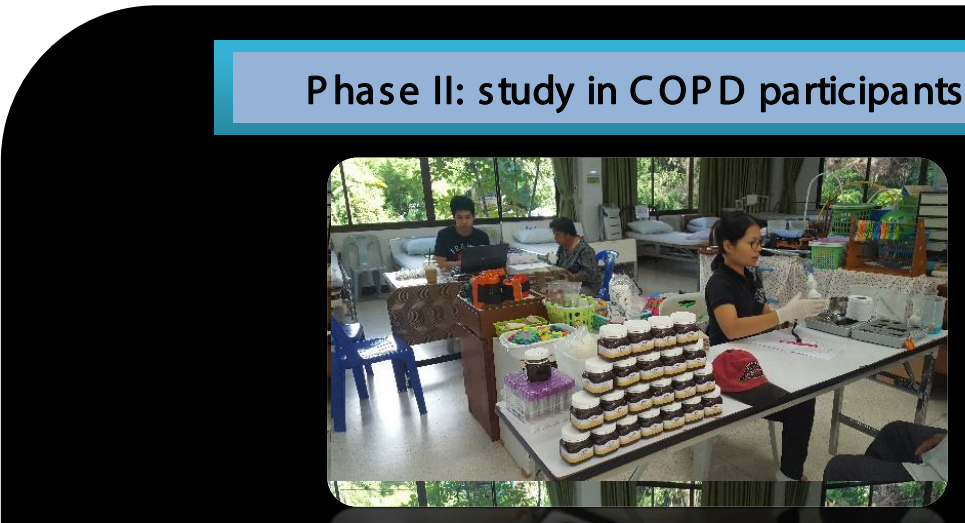

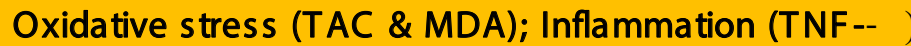
6-minutes walking distance (6MWD)

Plasma L-ascorbic acid \& oxalic acid

Renal function (creatinine \& BUN); F asting blood sugar (FBS)

Symptomatic adverse effects \& S atisfactory on product 


\section{ABOUT AUTHORS}

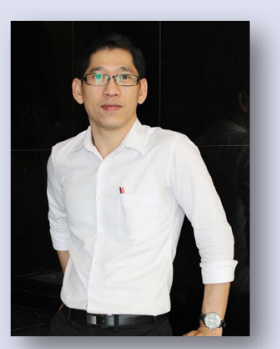

JIRAKRIT LEELARUNGRAYUB: Associate professor of Physical Therapy, Faculty of Associated Medical Sciences, Chiang Mai University. Got a Bachelor decree of Physical Therapy from Faculty of Associated Medical Sciences, Khon Kaen university, Master and Doctor degrees (Biochemistry) from Faculty of Medicine, Chiang Mai University. His Ph.D. thesis related to the oxidative stress and antioxidant areas under supervised by Assoc. Prof. Janusz Gebicki at Macquarie University, NSW, Australia. Presently, he is specialized study on cardiopulmonary rehabilitation, nutrition, exercise sciences and oxidative stress via inflammation and antioxidant condition in vitro and in human or patients. Published more than 38 international and 8 national articles and four reviewed chapters in the international textbooks.

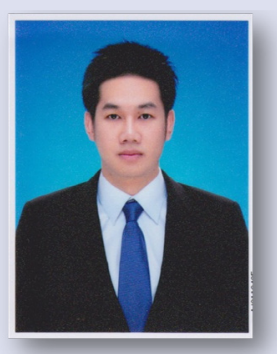

YOTHIN POTHASAK: He is a Physical Therapist. He finished his Bachelor degree of Physical Therapy from Department of Physical Therapy, Mae Fah Luang University, Chiang Rai, Thailand and got a funding grant under the Research and Researchers for Industries (RRi) during the study in Master degree of Movement and Exercise Sciences Program, Faculty of Associated Medical Sciences, Chiang Mai University, Thailand under supervised by Associate Professor Jirakrit Leelarungrayub.

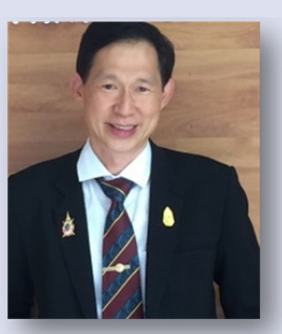

SURAPOL NATAKANKITKUL: Associate professor of Pharmaceutical Science, Faculty of Pharmacy, Chiang Mai University. He received his B.Pharm from Faculty of Pharmacy, Chiang Mai University. M.Pharm (Clinical and Hospital Pharmacy) from Faculty of Pharmaceutical Science, Chulalongkorn University, Bangkok. In 1991 he received Dr.rer.nat. (Biotechnology and Analytical Chemistry) under supervised by o-Univ. Prof. Dr. Günther K. Bonn, Innsbruck University, Austria. Research field: Pharmaceutical Science, Pharmacology, Toxicology and Phytocosmetics. Published more than 35 research articles in international journals. Supervision of 18 master degrees and $10 \mathrm{PhD}$ degrees of academic thesis. Now he is the President of the Society of Cosmetic Chemists of Thailand.

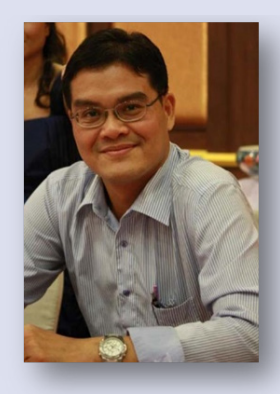

SUPAWACHARA SINGHATONG: Assistant Professor of MedicalTechnology, Division of Clinical Chemistry, Department of Medical Technology, Faculty of Associated Medical Sciences, Chiang Mai University. He received his B.Sc. (Medical Technology) from Faculty of Associated Medical Sciences, Chiang Mai University. M.Sc. (Toxicology) from Department of Forensic Medicine, Faculty of Medicine, Chiang Mai University. Ph.D. of Pharmacy from Faculty of Pharmacy, Chiang Mai University, Thailand. Research field: Toxicology, Antioxidant and Anti-inflammation.

Cite this article: PothasakY, Leelarungrayub J, Natakankitkul S, Singhatong S. Prototype Star Fruit-Honey Product and Effectiveness on Antixidants, Inflammation and Walking Distance in Participants with Stable Chronic Obstructive Pulmonary Disease (COPD). Pharmacogn J. 2020;12(5):1121-34. 